\title{
PRIMER
}

\section{Lyme borreliosis}

\author{
Allen C. Steere ${ }^{1,2}$, Franc Strle ${ }^{3}$, Gary P. Wormser ${ }^{4}$ Linden T. Hu ${ }^{5}$, John A. Branda, \\ Joppe W. R. Hovius ${ }^{7}$, Xin Li ${ }^{8}$ and Paul S. Mead
}

Abstract | Lyme borreliosis is a tick-borne disease that predominantly occurs in temperate regions of the northern hemisphere and is primarily caused by the bacterium Borrelia burgdorferi in North America and Borrelia afzelii or Borrelia garinii in Europe and Asia. Infection usually begins with an expanding skin lesion, known as erythema migrans (referred to as stage 1), which, if untreated, can be followed by early disseminated infection, particularly neurological abnormalities (stage 2), and by late infection, especially arthritis in North America or acrodermatitis chronica atrophicans in Europe (stage 3). However, the disease can present with any of these manifestations. During infection, the bacteria migrate through the host tissues, adhere to certain cells and can evade immune clearance. Yet, these organisms are eventually killed by both innate and adaptive immune responses and most inflammatory manifestations of the infection resolve. Except for patients with erythema migrans, Lyme borreliosis is diagnosed based on a characteristic clinical constellation of signs and symptoms with serological confirmation of infection. All manifestations of the infection can usually be treated with appropriate antibiotic regimens, but the disease can be followed by post-infectious sequelae in some patients. Prevention of Lyme borreliosis primarily involves the avoidance of tick bites by personal protective measures.

Lyme borreliosis is an important emerging infectious disease $\mathrm{e}^{1,2}$ that is commonly reported in North America and Europe, but is also found in parts of $\mathrm{Asia}^{3}$. The US Centers for Disease Control and Prevention estimates that $\sim 300,000$ new cases of the disease occur annually in the United States, primarily in northeastern states ${ }^{4}$.

Lyme arthritis was recognized in 1976 because of geographical clustering of children with arthritis in Lyme, Connecticut in the United States ${ }^{5}$. Following this report, Lyme arthritis was revealed to be part of a complicated multisystem illness, which included erythema migrans (a slowly expanding skin lesion), Bannwarth syndrome and acrodermatitis chronica atrophicans, which had been described in Europe ${ }^{1}$. These syndromes were brought together following the isolation of Borrelia burgdorferi, a spirochaete, from Ixodes scapularis (also known as Ixodes dammini ticks) ${ }^{6}$. In addition, B. burgdorferi was recovered from patients with these clinical manifestations of the infection ${ }^{1}$, and the disease, commonly affecting the skin, joints, heart or nervous system, is now referred to as Lyme borreliosis.

B. burgdorferi sensu lato (B. burgdorferi s.l.; that is, $B$. burgdorferi in the general sense) now comprises 20 different genospecies ${ }^{3}$. Three genospecies of B. burgdorferi s.l. are primarily responsible for human Lyme borreliosis: B. burgdorferi, Borrelia afzelii and Borrelia garinii ${ }^{7}$. These genospecies are transmitted by different species of ticks and are responsible for Lyme borreliosis in different geographical regions, for example, B. burgdorferi sensu stricto (that is, B. burgdorferi in the strict sense) is the primary cause of Lyme borreliosis in the United States, whereas B. afzelii and B. garini (and less often B. burgdorferi) cause Lyme borreliosis in Europe. The heterogeneity among B. burgdorferi s.l. strains seems to be the main factor causing the regional differences in the clinical expression of human Lyme borreliosis ${ }^{8}$. For example, B. burgdorferi in the northeastern United States is particularly arthritogenic, B. afzelii primarily causes skin infections and B. garinii is especially neurotropic ${ }^{2}$.

In this Primer, we detail the epidemiology, pathophysiology, clinical manifestations, prevention, management and post-treatment sequelae of the infection. Moreover, we provide an outlook for improved diagnostics, treatment studies, tick control and vaccination for this complex, tick-transmitted illness.

\section{Epidemiology}

In the United States, the age distribution of Lyme borreliosis is typically bimodal, with peaks among children $5-15$ years of age and adults $45-55$ years of age ( $^{3,9}$ (FIG. 1a). The incidence of Lyme borreliosis is higher among men than among women in those $<60$ years of age, but the sex ratio is nearly equal or slightly higher in women in older 
Author addresses

${ }^{1}$ Center for Immunology and Inflammatory Diseases, Division of Rheumatology, Allergy and Immunology, Massachusetts General Hospital, 55 Fruit Street, Boston, Massachusetts 02114, USA.

${ }^{2}$ Harvard Medical School, Harvard University, Boston, Massachusetts, USA.

${ }^{3}$ Department of Infectious Diseases, University Medical Center Ljubljana, Ljubljana, Slovenia.

${ }^{4}$ Division of Infectious Diseases, New York Medical College, Valhalla, New York, USA.

${ }^{5}$ Department of Molecular Biology and Microbiology, Tufts Medical Center, Boston, Massachusetts, USA. ${ }^{6}$ Department of Pathology, Massachusetts General Hospital, Boston, Massachusetts, USA.

${ }^{7}$ Center for Experimental and Molecular Medicine, University of Amsterdam, Amsterdam, The Netherlands.

${ }^{8}$ Division of Geographic Medicine and Infectious Diseases, Tufts Medical Center, Boston, Massachusetts, USA.

${ }^{9}$ Bacterial Diseases Branch, Division of Vector-Borne Diseases, Centers for Disease Control and Prevention, Fort Collins, Colorado, USA.

age groups. In some European countries, such as Slovenia and Germany, the incidence of Lyme borreliosis is higher among adult women (55\%) than among men $(45 \%)^{9-11}$. In the northeastern United States and in most of Europe, the peak months of disease onset are June and July, which is owing to the feeding habits of nymphal ticks (FIG. 1 b).

\section{Tick vectors and animal hosts}

Worldwide, four tick species belonging to the Ixodes ricinus complex are major vectors for the transmission of B. burgdorferi s.l. to humans ${ }^{12}$ (FIG. 2). The natural enzootic cycles of B. burgdorferi s.l. are complex and vary by geographical location. In the northeastern United States, transmission of B. burgdorferi occurs from some rodents, particularly white-footed mice and chipmunks, to larval and nymphal I. scapularis ${ }^{13}$. The fact that the larval and nymphal stages of the tick feed on the same animal is essential, as the life cycle of the spirochaete depends on horizontal transmission from infected nymphs to rodents in early summer and from infected rodents to larvae in late summer, which then moult to infected nymphs to begin the cycle the following year ${ }^{14}$. White-tailed deer, which are not involved in the life cycle of the spirochaete, are the primary host of adult I. scapularis and, as such, are the primary site of tick mating, and, therefore, are important for the maintenance of tick populations ${ }^{15}$. In Europe, I. ricinus feed on $>300$ animal species, including large and small mammals, birds and reptiles ${ }^{16}$. Birds are an important reservoir for B. garinii, whereas rodents are an important reservoir for B. afzelii. Migratory birds might have a role in expanding the range of ticks to new areas ${ }^{12}$, as has been observed in central and eastern Canada ${ }^{17}$.

\section{Distribution and incidence}

Lyme borreliosis has been reported in countries throughout the northern hemisphere. In Europe and Asia, the reported country-wide incidence ranges from low to negligible in the United Kingdom, Turkey and Japan, to $>80$ cases per 100,000 individuals in the Netherlands, Belgium, Austria, Slovenia, Lithuania and Estonia ${ }^{10,18}$. Data on the incidence of Lyme borreliosis are scarce from Asia, although cases have been reported in, for example, China and Mongolia ${ }^{19}$. In North America, $>90 \%$ of cases are reported from two regions in the United States: the northeast and mid-Atlantic region and the north-central region ${ }^{9,12,20}$. Both regions have expanded substantially over the past 20 years $^{20}$ and have reached the southern parts of Canada ${ }^{21}$. Pockets of intense transmission of B. burgdorferi can exist within smaller, well-defined areas and in individuals who are at high risk for tick bites, such as hikers or forestery workers ${ }^{9,11}$. In a trial investigating a Lyme disease vaccine that was conducted in such areas of the northeastern United States, the yearly incidence of $B$. burgdorferi was $>1$ per 100 participants in the placebo group ${ }^{22}$.

\section{Risk factors}

Within an endemic area, the risk of human infection by B. burgdorferi s.l. is determined by the local abundance and infection rate of vector ticks and by human behaviours that affect the likelihood of being bitten. Occupations and hobbies that increase tick exposure (for example, forestry workers, hunters and hikers) are associated with an increased risk of infection ${ }^{20,23,24}$. Where homes are situated in tick-infested areas, exposure occurs primarily in the peridomestic environment that is influenced by the amount of suitable tick habitat, the density of ticks and deer, landscaping practices that promote tick survival and the undertaking of outdoor activities, such as gardening ${ }^{25}$. Infection through alternate modes of transmission, including blood transfusion, sexual contact, semen, urine or breast milk, has not been demonstrated.

\section{Mechanisms/pathophysiology}

Most mechanistic studies of B. burgdorferi s.l. have been carried out in mouse models using strains of B. burgdorferi that are found in the United States. However, several caveats are associated with the translation of findings in mouse models to human Lyme borreliosis. First, although B. burgdorferi infection shows a reproducible temporal progression in mice as the organism disseminates from the inoculation site, disease in inbred strains of mice does not closely mimic human Lyme borreliosis. Second, the pathogenic characteristics of B. burgdorferi might not be identical for all of the genospecies that cause Lyme borreliosis. Thus, except for instances in which a given characteristic is known to apply to all B. burgdorferi s.l. genospecies, we use the term $B$. burgdorferi throughout this section and we do not equate pathological characteristics with a stage of the human disease, unless we are reporting features of the human infection.

\section{B. burgdorferi cellular architecture}

Like all spirochaetes, members of the B. burgdorferi s.l. complex are bound by an inner cytoplasmic membrane and an outer membrane. The defining characteristic of $B$. burgdorferi s.l. is periplasmic flagella, which are 
responsible for the flat-wave morphology of the bacteria. The flagella are attached to each cell pole and wind around the cell cylinder in the periplasmic space between the peptidoglycan layer and the outer membrane $^{26}$ (FIG. 3a,b). Flagellar motors are located at the cell poles and are situated next to the methyl-accepting chemotaxis proteins that direct movement of the bacteria towards chemoattractants (for example, nutrients such as rabbit serum and $N$-acetylglucosamine) and away from repellants (for example, ethanol and butanol) ${ }^{27-29}$.

B. burgdorferi differs considerably from typical Gram-negative bacteria. Notably, the outer membrane lacks lipopolysaccharide and consists of a lipid bilayer that is composed of phospholipids and glycolipids ${ }^{30}$ (FIG. 3c). Cholesterol glycolipids in the outer membrane

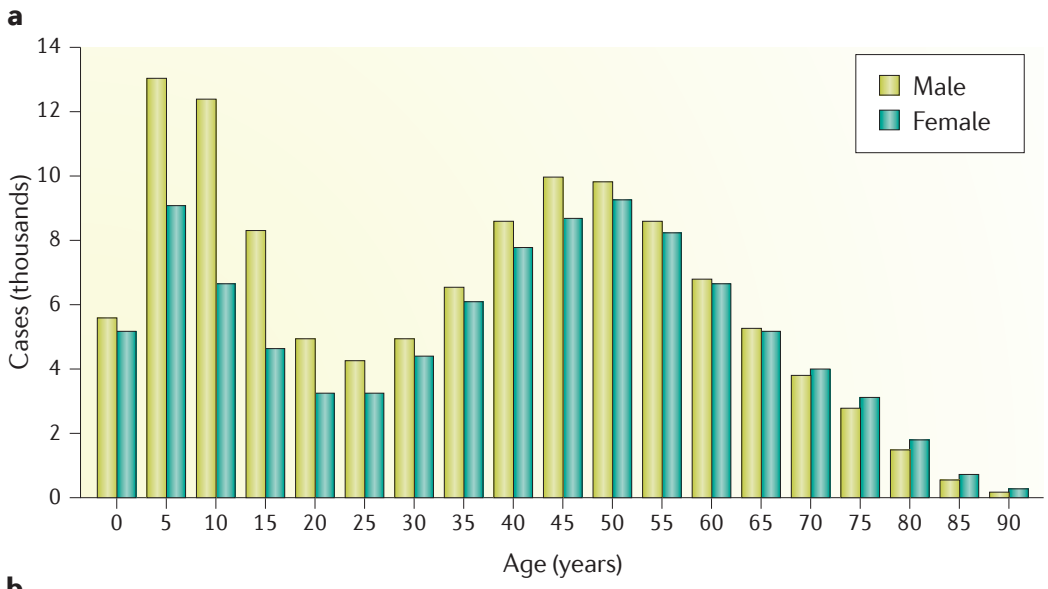

b

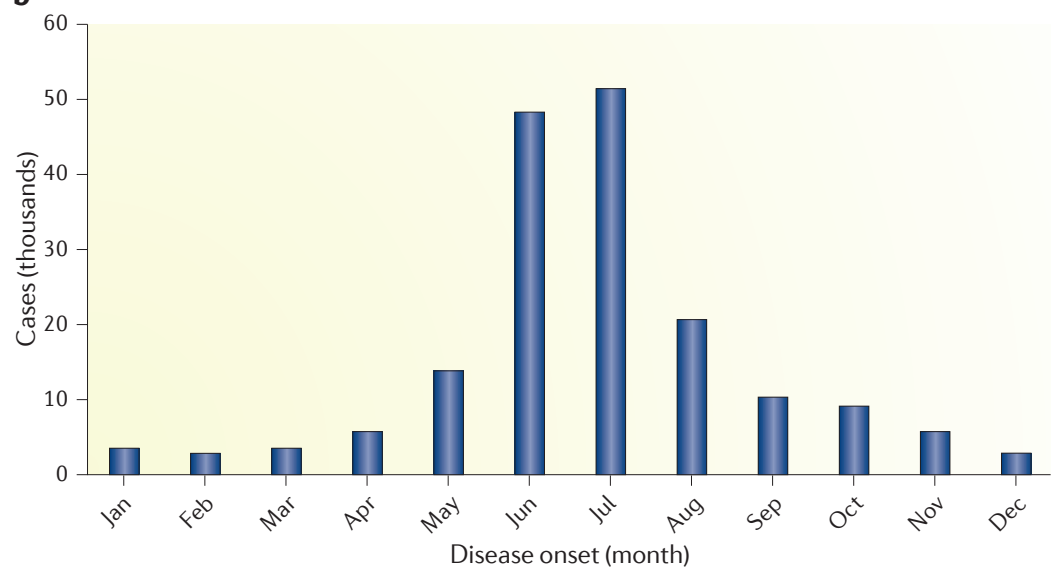

Figure 1 | Age and sex distribution and seasonality of Lyme borreliosis. a |Among cases of Lyme borreliosis reported to the US Centers for Disease Control and Prevention in 2010-2013, the peak of ages of disease onset were 5-15 and 45-55 years of age. In individuals $<60$ years of age, Lyme borreliosis was more prevalent among males than females, but for those $>60$ years of age, the sex ratio was nearly equal or was higher in women. $\mathbf{b}$ |Nymphal ticks are a key source of human infection with Borrelia burgdorferi and typically feed in the late spring or early summer, which produces a June-July peak in human illness in the United States. In most of Europe, the peak months of onset are also June and July, but a later peak in August has been reported in Estonia and Sweden, perhaps owing to the northern latitudes of these countries ${ }^{11,217}$. In milder climates, such as California, the onset might be more spread out over spring and summer months ${ }^{3}$. Smaller regional and year-to-year variations in human illness have been correlated with meteorological conditions that influence tick feeding and human behaviour, such as temperature, humidity and rainfall ${ }^{218}$. These figures were obtained from the Centers for Disease Control and Prevention: http://www.cdc.gov/lyme/stats/graphs.html. form lipid-raft-like microdomains that change in order and size in response to temperature, which is an important environmental cue for B. burgdorferi during transmission between the tick vector and the mammalian host $^{31}$. The B. burgdorferi outer membrane also contains surface lipoproteins, which can change depending on the environment. For example, outer-surface protein A (OspA) is expressed during tick colonization and OspC is expressed during early infection of the mammal ${ }^{32-34}$.

\section{B. burgdorferi genome and metabolism}

All genospecies of the B. burgdorferi s.l. complex have small, highly segmented genomes. The 1.5 million-base genome of B. burgdorferi strain B31 consists of a linear chromosome of 910 kilobases, 9 linear plasmids and 12 circular plasmids of various sizes ${ }^{35,36}$. The linear chromosome is highly conserved among B. burgdorferi s.l. genospecies, whereas the plasmids show a high degree of variation. Although sequence data on plasmids are often incomplete, available data indicate that some plasmids in B. burgdorferi are missing in B. afzelii and B. garinii. Differences in plasmids among B. burgdorferi s.l. are thought to contribute to the clinical variability in Lyme borreliosis in different geographical regions.

Intraspecies diversity has also been noted for several B. burgdorferi s.l. genospecies ${ }^{8}$. For example, in the United States, B. burgdorferi strains have been divided into several subtypes ${ }^{8}$ based on variations in the genes that encode OspC, 16S-23S rRNA intergenic spacer region or eight selected housekeeping genes. This subtyping has been used to correlate the strain variation with the risk for haematogenous dissemination and clinical outcome $\mathrm{e}^{37-39}$.

B. burgdorferi has a very limited metabolic capacity and is highly dependent on its tick vector and vertebrate host for many essential factors. For example, B. burgdorferi lacks genes encoding proteins that have a role in the tricarboxylic acid cycle and oxidative phosphorylation, and relies exclusively on glycolysis for energy production. For this purpose, B. burgdorferi uses several host or vector-derived carbohydrates, including glucose, glycerol, maltose, $\mathrm{N}$-acetylglucosamine, trehalose and chitobiose $^{40}$. The $B$. burgdorferi genome also lacks genes that are required for the synthesis of amino acids, lipids, nucleotides and cofactors; to obtain these factors, the $B$. burgdorferi genome encodes 16 distinct membrane transporters, many of which have broad substrate specificity ${ }^{35}$. Owing to the inability of B. burgdorferi to synthesize fatty acids, its lipid composition reflects that of the host tissues ${ }^{41}$; B. burgdorferi exchanges lipids with the plasma membrane of eukaryotic cells, either through direct contact or via outer membrane vesicles ${ }^{42}$.

\section{Invasion, dissemination and immune evasion}

B. burgdorferi uses differential gene expression for survival in the different environments of the tick vector and the mammalian host. After tick attachment to the host, cues from tick engorgement (that is, the process of a tick taking a blood meal), such as increases in temperature, the availability of nutrients, changes in oxygen tension and decreased $\mathrm{pH}$, stimulate $B$. burgdorferi in the tick 


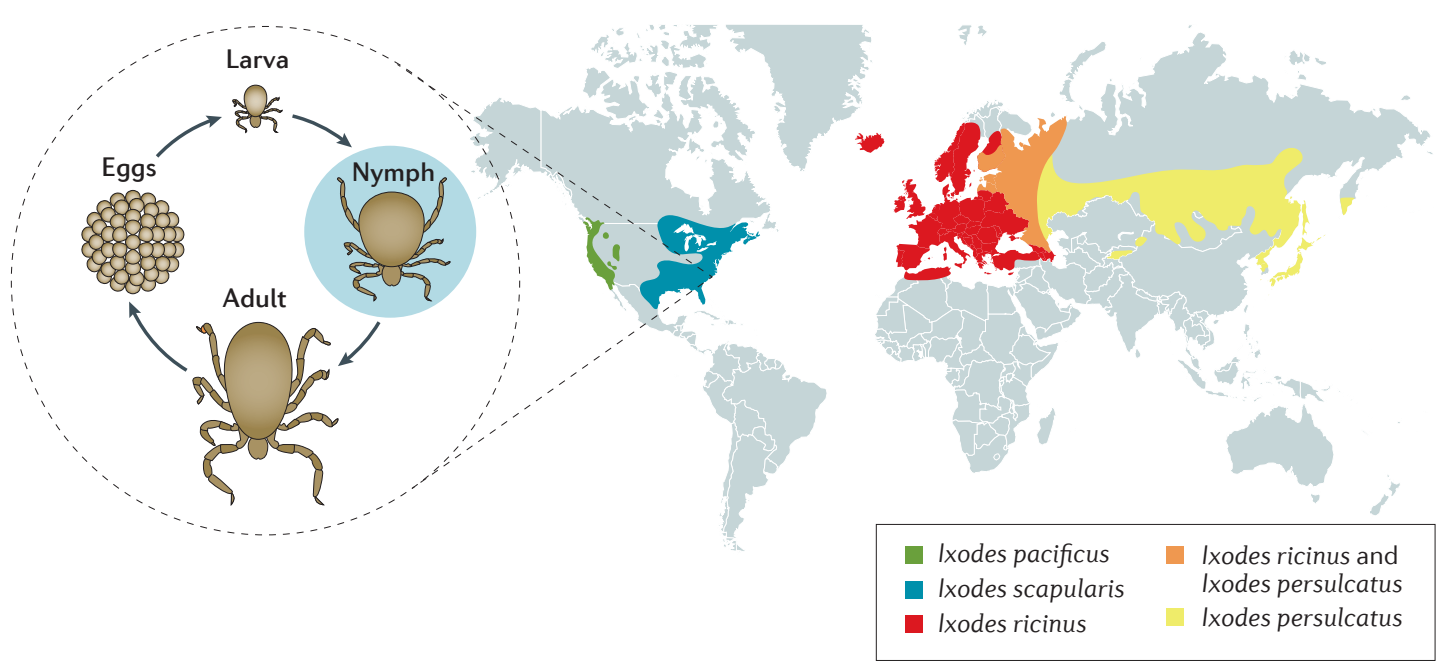

Figure 2 | Distribution of Ixodes ticks that transmit Borrelia burgdorferi s.l. to humans. Borrelia burgdorferi s.l. are transmitted by ticks of the Ixodes ricinus complex. In Europe, the principal tick vector is I. ricinus (red), which transmits all three major pathogenic genospecies of B. burgdorferi s.l. The tick Ixodes persulcatus (yellow), is found in western Russia, the Baltic countries, parts of Finland, central regions of eastern Russia, northern Mongolia, China and Japan. I. persulcatus transmits Borrelia afzelii and Borrelia garinii, but is not known to transmit B. burgdorferi ${ }^{219,220}$. In eastern Europe, I. ricinus and I. persulcatus overlap (orange). In North America, the main tick vectors are Ixodes scapularis in the eastern and mid-western United States (blue) and some areas in middle southern and southeastern Canada ${ }^{12,221,222}$ and Ixodes pacificus in the western United States (green) ${ }^{9,12}$; both of these ticks transmit B. burgdorferi. Within these broad areas, tick abundance and infection prevalence vary widely and are influenced by microclimate, vegetation and the abundance of reservoir vertebrate hosts. The regions of most intense transmission of B. burgdorferi s.l. are in the northeastern United States and in central Europe ${ }^{3}$, where the prevalence of B. burgdorferi s.l. infection among ticks can be as high as $40-50 \%$. By contrast, infection prevalence in the southern United States is $<1 \%$. The life cycle of ticks is illustrated in the inset. Larvae, nymph and adult are the main life stages (illustrated as would be seen with magnification), but each stage of each of these species is nearly identical in appearance. The tiny nymphal stage, which feeds in the late spring and early summer, is primarily responsible for transmission of the disease.

midgut to undergo transformation from a state that is adapted for tick colonization to one that is primed for infection of the mammal. This transformation requires a complex regulatory network that includes but is not limited to the expression of the RNA polymerase alternative $\sigma$-factor RpoS and Borrelia oxidative stress regulator (BosR) $)^{32,33}$ (FIG. 3c). A large number of genes that are targeted by RpoS and BosR encode surface lipoproteins, and RpoS and BosR act in concert to promote the adaptation of B. burgdorferi to the mammalian host through transcriptional activation of mammalian-phase-specific genes (for example, ospC) by $\mathrm{RpoS}^{43}$ and transcriptional repression of the tick-phase-specific genes (for example, ospA) by BosR ${ }^{44}$. Replacing OspA (a tick midgut adhesin ${ }^{45}$ ) with OspC is crucial for establishing early infection in the mammal ${ }^{33,46}$.

The establishment of $B$. burgdorferi infection in the host is substantially aided by the tick in both mechanical and biochemical ways. Mechanically, the penetration of the host's skin by the tick enables the delivery of B. burgdorferi deep into the dermis, near the blood vessels. Biochemically, tick salivary proteins help B. burgdorferi establish an infection by modulating host activities, such as coagulation, fibrinolysis and the immune response ${ }^{47}$. One of the mechanisms by which OspC enhances bacterial colonization of a mammalian host is through direct recruitment of the tick salivary protein Salp15, a molecule with immunosuppressive properties, to the bacterial surface ${ }^{48}$. After being deposited in the skin, B. burgdorferi usually multiplies locally before spreading through tissues and into the blood or lymphatic system, which facilitates migration to distant sites. Motility (generated by the flagella) and adherence to host molecules (mediated by the surface lipoproteins) are key to B. burgdorferi moving through the host's blood and tissues and evading immune responses. Mutant bacteria that have defects in motility or chemotaxis fail to disseminate and are quickly cleared from the inoculation site ${ }^{26}$.

Many of the mammalian-phase-specific surface lipoproteins can directly interact with several host macromolecules, including plasminogen, complement regulatory proteins and components of the extracellular matrix, such as fibronectin, collagen, laminin and glycosaminoglycans (GAGs) ${ }^{49,50}$. These interactions are thought to have distinct functions, such as plasminogen for proteolysis of tissues, extracellular matrix molecules for adhesion and complement regulatory proteins for immune evasion. However, there is a high degree of functional redundancy among these $B$. burgdorferi lipoproteins, which makes it difficult to ascertain the in vivo significance of each protein. An exception is the fibronectin-binding protein BBK32, in which unique and sequential roles are assigned to the fibronectinbinding and GAG-binding domains in the interaction of $B$. burgdorferi with the host vasculature ${ }^{51}$. BBK32fibronectin binding initiates the 'tethering' of circulating 
a

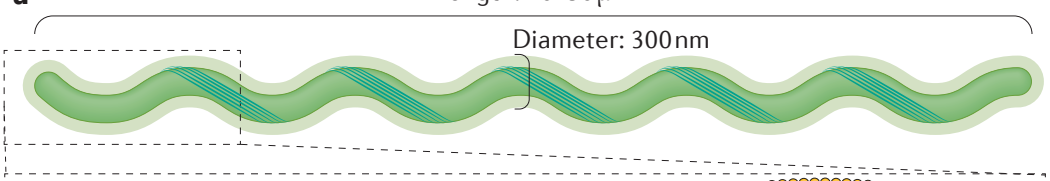

b

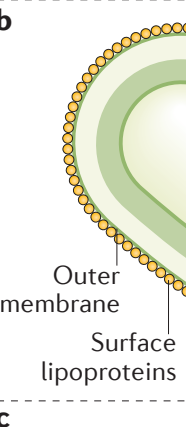

C

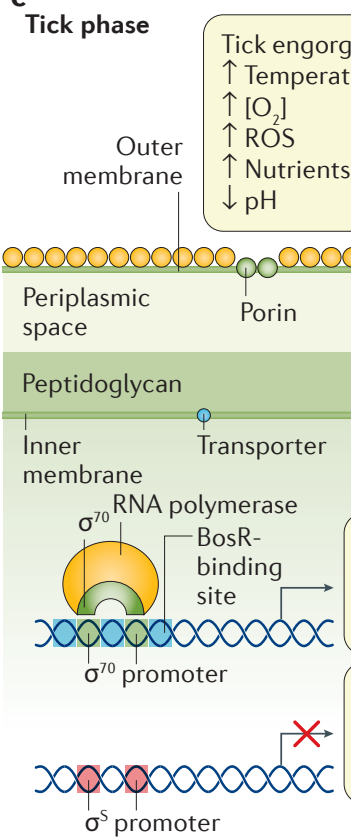
Peptidoglycan
Periplasmic space
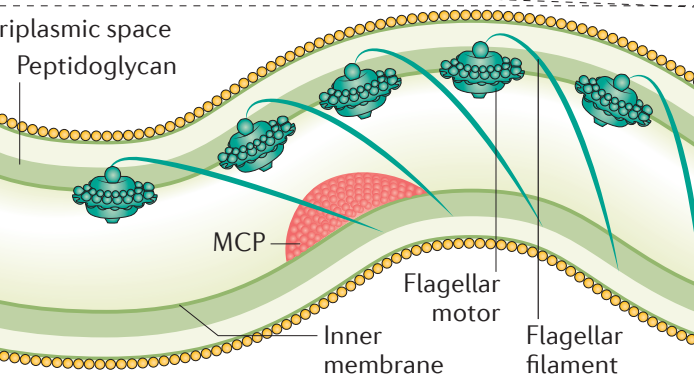

4 Flagella Inner membrane motor Flagellar filament

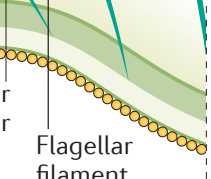
- . . . . . . . . .

B. burgdorferi to the vascular surface and BBK32-GAG binding contributes to a more-stable vascular interaction, after which $B$. burgdorferi transmigrates across the endothelium and disseminates into tissues.

B. burgdorferi uses several strategies for evading the host innate and adaptive immune systems. Several B. burgdorferi lipoproteins, which are known collecteins (CRASPs), can bind to host factor $\mathrm{H}$, factor $\mathrm{H}$-like protein and factor $\mathrm{H}$-related proteins $\mathrm{s}^{52,53}$, which prevents complement-mediated killing of the bacteria in vitro ${ }^{5,53}$. After the establishment of infection, the evasion of bacthe bacteria. For this purpose, B. burgdorferi again alters the lipoproteins that are expressed on its outer surface, tively as complement regulator-acquiring surface protericidal antibodies becomes crucial for the survival of by replacing OspC with VlsE. On the basis of structural similarities between OspC and VlsE, these two proteins might serve a similar physiological function. However, unlike OspC, VlsE undergoes extensive antigenic variation to evade the host immune response $e^{54}$. Millions of $v l s E$ alleles can be generated through gene conversion, which occurs when segments of the 15 silent $v l s$ loci are assembled into the $v l s E$ locus in random combinations. The highly variable segments of VlsE are located in a 'dome' region that is distal to the lipid anchor and exposed on the cell surface. B. burgdorferi can evade host antibodies to one VlsE variant by expressing a different one on the surface (FIG. 3c). Mutants that express nonvariable VlsE are unable to reinfect animals that have been previously infected with $B$. burgdorferi, whereas bacteria that express variable VlsE $\mathrm{can}^{55}$.

\section{The host immune response}

Despite the expression of CRASPs and the antigenic variation of $B$. burgdorferi surface lipoproteins that enable the bacteria to evade host immune defences, $B$. burgdorferi is still recognized and killed by both innate and adaptive immune responses. As B. burgdorferi does not produce toxins or extracellular matrix-degrading proteases, most of the manifestations of human Lyme borreliosis at each of the three stages of disease result from inflammation generated by these immune responses.

In stage 1 (in humans, this is typically an expanding skin lesion known as erythema migrans), biopsies that are taken during the first days of infection show papillary dermal oedema and a mixed infiltrate that consists predominantly of $\mathrm{T}$ cells, neutrophils, dendritic cells and monocytes or macrophages ${ }^{56}$. Cytokine expression during this stage is predominantly proinflammatory and includes increased levels of tumour necrosis factor (TNF), IL-2, IL-6 and type I interferons $(\mathrm{IFNs})^{57-59}$. The levels of chemokines that attract neutrophils (such as CXC-chemokine ligand 1 (CXCL1; also known as growth-regulated- $\alpha$ protein)), macrophages (such as CC-chemokine ligand 3 (CCL3) and CCL4) and T cells (such as CXCL9, CXCL10 and CXCL11) are also increased in erythema migrans lesions $s^{60}$. In both animal and human studies, neutrophils, which are highly effective at killing $B$. burgdorferi, are notably absent as the erythema migrans rash progresses past 24 hours, whereas $\mathrm{T}$ cells, dendritic cells and monocytes 
remain ${ }^{59,61}$. In animals that artificially express increased levels of the neutrophil chemoattractant KC, B. burgdorferi is rapidly cleared following incoculation to the dermis, which suggests that the disappearance of neutrophils is important for permitting the establishment of the infection ${ }^{62}$. Complement also plays an early part in controlling the infection, probably by augmenting phagocytosis and opsonization through the classical pathway. As erythema migrans lesions evolve over days, they progress to dense perivascular and interstitial infiltrates that consist of lymphocytes, plasma cells and occasionally mast cells ${ }^{56}$. The anti-inflammatory cytokine IL-10 can be found in these lesions and higher levels of IL-10 have been associated with fewer systemic symptoms of Lyme borreliosis ${ }^{57,63}$. In animals, IL-10 deficiency is associated with increased inflammation and decreased numbers of B. burgdorferi ${ }^{64}$, suggesting that, although IL-10 induction might lead to less inflammation and tissue damage, this might enable $B$. burgdorferi to escape the immune system.
Much of the initial host inflammatory response seems to be mediated by pathogen-associated molecular patterns (PAMPs) that are detected by pattern recognition receptors, such as Toll-like receptors (TLRs) and the cytosolic nucleotide-binding oligomerization domaincontaining protein (NOD)-like receptors (FIG. 4). Different TLRs can recognize different PAMPs of B. burgdorferi, including but not limited to lipoproteins (detected by TLR1 and TLR2) ${ }^{65-67}$, flagellin (detected by TLR5) ${ }^{68}$, RNA (detected by TLR7 and TLR8) ${ }^{69,70}$ and CpG sites in DNA (detected by TLR9) ${ }^{68,69}$. However, responses to B. burgdorferi lipoproteins seem to be the main stimulus causing induction of host enzymes that result in the digestion of extracellular matrix proteins, allowing bacteria to move within tissues and the release of inflammatory cytokines, which leads to the symptoms of Lyme borreliosis ${ }^{71}$. Studies of knockout mice have shown a role for some TLRs and adaptors (including TLR2 (REF. 72) and the myeloid differentiation primary response protein MYD88 (REFS 73-75)), but not all ${ }^{76-78}$, in control of the infection.

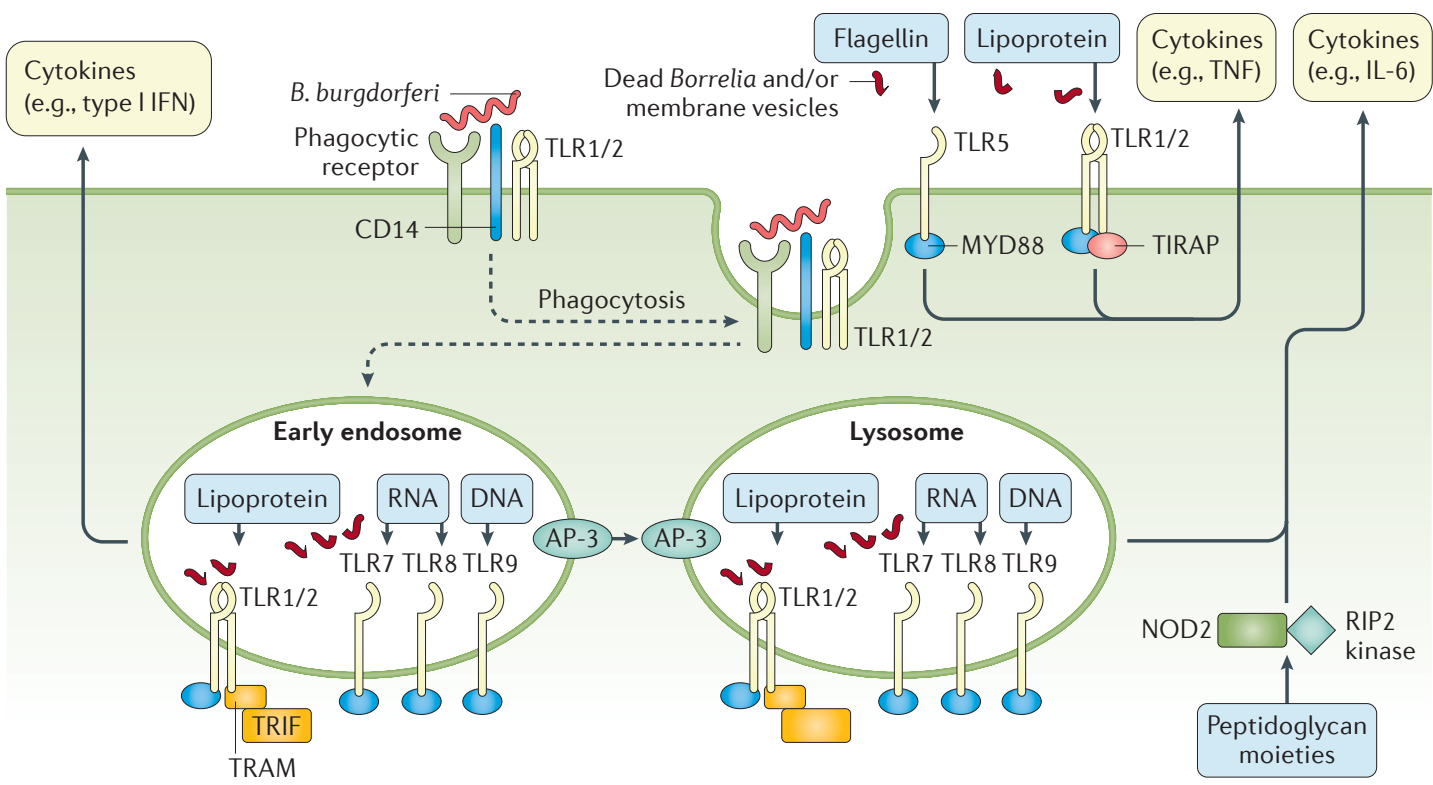

Figure 4 | Mechanisms of innate immune recognition of Borrelia burgdorferi. The initial innate immune response is triggered by recognition of Borrelia burgdorferi or its pathogen-associated molecular patterns (PAMPs) by host immune cells, for example, dendritic cells and macrophages or monocytes. These cells express pattern recognition receptors, particularly Toll-like receptors (TLRs) and nucleotide-binding oligomerization domain-containing protein (NOD)-like receptors (NLRs). Some TLRs, including TLR1/2 heterodimers and TLR5, bind to their ligand on the cell surface, which results in the activation of a regulatory cascade that leads to the production of specific cytokines and chemokines. TLR1/2, along with other TLRs (such as TLR7, TLR8 and TLR9), can also be activated after phagocytosis of the organism and signal from within endosomes. Several different molecules that are involved in phagocytosis have been identified, including complement receptor 3, CD14 and the macrophage receptor MARCO. The exact cytokines produced as a result of these interactions are probably dependent on the specific endosome and/or adaptors and effectors that are recruited to that site. NLRs (for example, NOD2) recognize B. burgdorferi or its PAMPs in the cytosol and can increase cytokine induction by activation of TLRs. The balance of pro-inflammatory and anti-inflammatory cytokine production evolves over time and shifts towards an increased production of anti-inflammatory cytokines, such as IL-10, which limits tissue pathology. Signalling is mediated through the recruitment of adaptor molecules, such as the myeloid differentiation primary response protein MYD88, TIR domain-containing adaptor molecule 1 (TRIF), Toll/IL-1 receptor domain-containing adaptor protein (TIRAP) and receptor-interacting serine/threonine-protein kinase 2 (RIP2), which help to transduce signals from receptors to effector molecules, such as interferon (IFN) regulatory factor 3 (IRF3), IRF7 and nuclear factor- $\mathrm{kB}$ - each of which can result in the production of different subsets of cytokines. The dashed arrows represent predictions for which there are currently no experimental evidence. AP-3, adaptor protein complex 3; TRAM, TRIF-related adapter molecule (also known as TICAM2); TNF, tumour necrosis factor. 
Although deficiencies in TLRs or their adaptors can result in reduced induction of inflammatory cytokines upon exposure to B. burgdorferi in vitro, a deficiency in one TLR or adaptor does not diminish inflammation during infection in animals, and might even result in increased inflammation, as observed in mice deficient in the TLR components TLR2, MYD88, TIR domain-containing adapter molecule 1 (TRIF) or CD14 (REFS $66,67,73,76$ ). This finding suggests that there is redundancy in the ability of the innate immune system to recognize B. burgdorferi and/or that these components can activate pathways that produce anti-inflammatory cytokines, such as IL-10. During later stages of infection - namely, stage 2 (in humans known as early disseminated infection that is manifested by inflammation at multiple sites) and stage 3 (in humans known as late infection, typically involving arthritis in the United States) - the anti-inflammatory effects might be the more important function of TLR signalling ${ }^{79,80}$. In human Lyme arthritis, a polymorphism in TLR1 (which results in decreased expression of TLR1) is associated with increased levels of pro-inflammatory cytokines and persistent arthritis after antibiotic therapy ${ }^{39}$. This high level of cytokines parallels the phenotype of untreated innate immune-deficient mice, but mice do not develop persistent arthritis after antibiotic therapy. This phenotype might result from persistent stimulation from residual TLR ligands, either pathogen or host-derived, leading to continued receptor activation.

As the organism disseminates from the original inoculation site, the pattern of recruitment of inflammatory cells, the release of cytokines and inflammation continue at the sites where the bacteria localize, including the heart, joints and nervous system. All affected tissues show mononuclear cell infiltrates, particularly $\mathrm{CD}^{+}$and $\mathrm{CD} 8^{+} \mathrm{T}$ cells, and vascular abnormalities, suggesting that spirochaetes were located in or around blood vessels ${ }^{81}$. In animal models, differences in the inflammatory infiltrates at different sites of infection, as well as at different stages of the disease, have been observed $^{82}$. For example, macrophages are abundant in cardiac lesions, but B cells and plasma cells are plentiful in synovial lesions. In stage 3 , synovial lesions in patients with antibiotic-refractory Lyme arthritis show synovial cell hypertrophy, vascular proliferation and sometimes obliterative microvascular lesions, in addition to mononuclear cell infiltrates, which primarily consist of $\mathrm{CD}^{+}$and $\mathrm{CD} 8^{+} \mathrm{T}$ cells and macrophages, often with large numbers of plasma cells ${ }^{83}$.

In in vitro studies, phagocytic cells, including macrophages, monocytes, neutrophils, dendritic cells and microglia, can effectively kill B. burgdorferi. Both $\gamma \delta \mathrm{T}$ cells and natural killer T cells (NKT cells) are recruited quickly to sites where bacteria are present and seem to be involved in modulating antibody responses to the bacteria. The diacylglycerol glycolipid in the outer membrane of the spirochaete can directly activate invariant NKT cells, which have an important role in controlling infection and augmenting phagocytosis ${ }^{84}$.

B cells are crucial for the control of infection. In the spleen, marginal zone B cells produce antibodies to $\mathrm{T}$ cell-independent antigens and are a source of B. burgdorferi-specific IgM antibodies during stage 1 of the disease $\mathrm{e}^{85}$. Subsequent development of B. burgdorferispecific IgG antibodies is correlated with a reduction in spirochaetal numbers in mice, and passively administered IgG antibodies can prevent the establishment of infection in animal models ${ }^{33}$. Probably owing to variability of proteins among strains of B. burgdorferi, many antibodies against specific proteins are only able to prevent infection in isogenic strains.

Within several weeks to months, innate and adaptive immune mechanisms can reduce bacterial numbers such that, even without antibiotic treatment, the systemic symptoms of Lyme borreliosis wane. Spirochaetes might survive in localized niches in untreated patients for several more years, which can cause persistent symptoms in some cases. However, in humans, all of the inflammatory manifestations of disease, with the possible exception of acrodermatitis chronica atrophicans, resolve eventually, even without antibiotic therapy. Wild-life reservoirs of B. burgdorferi, such as mice, do not develop any pathology related to the infection, despite lifelong persistence of the bacteria. This finding suggests that their immune systems have evolved to 'ignore' the presence of the organism, which, because the bacteria do not produce toxins or degradative factors, poses less of a threat than continued activation of the immune system. In humans, who are not reservoir hosts, the bacteria, although able to escape killing in localized niches for months or years, are more-efficiently cleared.

\section{Diagnosis, screening and prevention}

Except for erythema migrans, which is usually diagnosed clinically, the other manifestations of Lyme borreliosis are typically diagnosed by recognition of characteristic clinical signs and symptoms along with serological testing ${ }^{2}$. Without antibiotic therapy, the clinical manifestations of the disease typically occur in three stages, beginning with early localized infection of the skin and ending with late infection, most commonly Lyme arthritis in the United States or acrodermatitis chronica atrophicans in Europe.

\section{Clinical manifestations}

In all parts of the world with endemic Lyme borreliosis, the infection typically begins during summer with erythema migrans (stage 1), which occurs at the site of the tick bite (FIG. 5). In the United States, where the infection is caused by B. burgdorferi, erythema migrans is often accompanied by malaise, fatigue, headache, arthralgias, myalgias, fever and regional lymphadenopathy ${ }^{86}$. In addition, erythema migrans is the presenting manifestation of Lyme borreliosis in $\sim 80 \%$ of patients in the United States; $\sim 18 \%$ of patients have nonspecific symptoms during summer without recognition of erythema migrans and the remaining $2-3 \%$ present with a manifestation of early or late disseminated infection, such as facial palsy, trigeminal neuropathy or Lyme arthritis ${ }^{87}$. Even without antibiotic therapy, erythema migrans typically improves or resolves within weeks. 
In Europe, erythema migrans caused by any of the B. burgdorferi s.l. genospecies expands slower than that evident in cases in the United States and is not usually accompanied by other symptoms. Interestingly, the clinical features of $B$. burgdorferi infection in Europe more closely resemble that of infection with $B$. afzelii or B. garinii, which share the same ecological niche, than the clinical features of $B$. burgdorferi infection in the United States ${ }^{88}$. Although B. garinii infection also begins in most cases as a solitary skin lesion, itching and burning symptoms within the lesion are more common and local spreading is faster than with $B$. afzelii or B. burgdorferi infection in Europe ${ }^{89,90}$. A rare skin manifestation of early Lyme borreliosis in Europe is borrelial lymphocytoma, which is typically located on the earlobe in children or on the nipple in adults (FIG. 5b) and is most often caused by B. afzelii infection ${ }^{91}$.
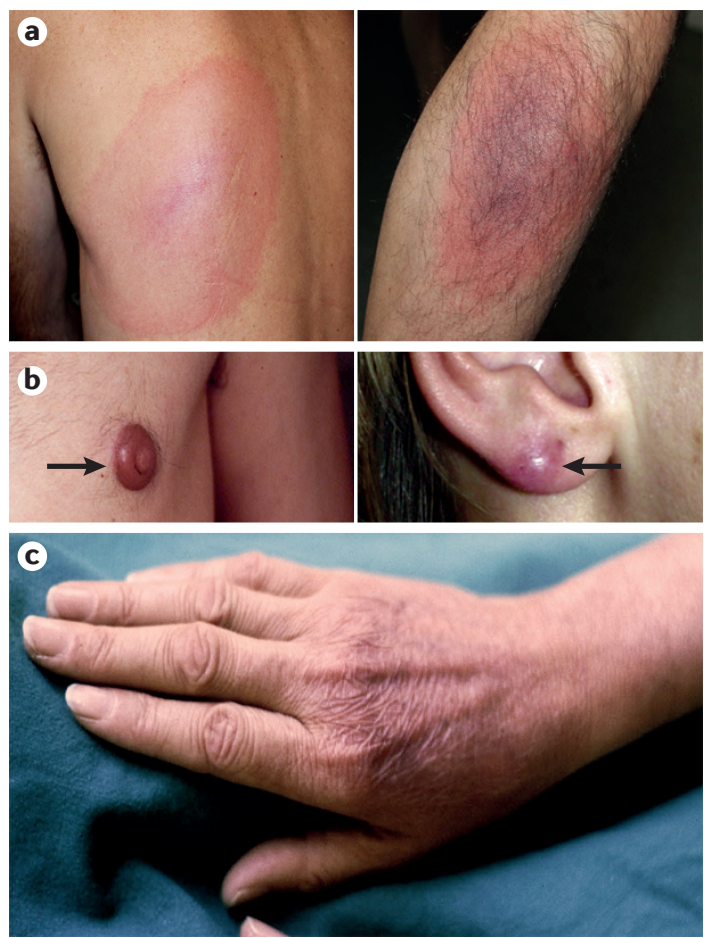

Figure 5 | Dermatological manifestations of Lyme borreliosis. All pathogenic Borrelia burgdorferi s.l. genospecies typically cause an expanding skin lesion known as erythema migrans, which occurs at the site of the tick bite. a | Classic erythema migrans lesions, with a brighter red outer border, partial central clearing and a bull's eye centre. Other erythema migrans lesions can have a more-intense inflammation and purplish discolouration in the centre. $\mathbf{b}$ | Borrelial lymphocytoma (arrows) is a subacute lesion that typically occurs on the nipple in adults or on the earlobe in children. $\mathbf{c}$ |Acrodermatitis chronica atrophicans is the most common late manifestation of Lyme borreliosis in Europe. These lesions have an inflammatory phase with a reddish or blue colour followed by an atrophic phase, in which the skin thins considerably, sometimes with fibrotic features. Borrelial lymphocytoma and acrodermatitis chronica atrophicans have been noted in Europe and Asia, but not in North America.
Early disseminated infection. Within days to weeks, the strains of B. burgdorferi in the United States commonly disseminate from the site of the tick bite to other regions of the body. B. burgdorferi can spread to other skin sites, causing multiple erythema migrans lesions, or to other organs, particularly to the peripheral and/or central nervous system (CNS), heart or joints ${ }^{2}$ (FIG. 6). B. afzelii does not disseminate as often as $B$. burgdorferi, but can persist at skin sites, for months or years, either at the site of the previous tick bite or at other sites, whereas B. garinii is particularly neurotropic and may cause both peripheral nervous system (radiculoneuritis, that is, inflammation of the spinal nerve root) and CNS (meningitis) abnormalities.

During early disseminated infection (stage 2), patients might develop acute Lyme neuroborreliosis ${ }^{1}$. In the United States, the most common clinical features of Lyme neuroborreliosis are lymphocytic meningitis with episodic headaches and mild neck stiffness, cranial neuropathy (particularly facial palsy), or motor or sensory radiculoneuritis ${ }^{92}$. Rarely, patients might have cerebellar ataxia or encephalomyelitis ${ }^{92}$. Electrophysiological studies of peripheral nerve lesions in affected extremities (that is, the extremities that are innervated by branches of the spinal nerve with radiculoneuritis) suggest primarily axonal nerve involvement ${ }^{92,93}$. Histologically, these lesions show axonal injury with perivascular infiltration of lymphocytes and plasma cells around epineural blood vessels ${ }^{93}$.

In Europe, B. garinii infection causes a type of neurological involvement, called Bannwarth syndrome or tick-borne meningopolyneuritis ${ }^{94}$. Bannwarth syndrome begins with painful radiculoneuritis that is associated with lymphocytic meningitis, often without headache, and can be followed by cranial neuropathy or pareses of the extremities ${ }^{95}$. B. afzelii can also cause neurological involvement, but the clinical manifestations are not as clear as with $B$. garinii ${ }^{96}$. Of 10 patients in whom B. afzelii was isolated from cerebrospinal fluid (CSF), only one fulfilled criteria for confirmed Lyme neuroborreliosis, which is defined as an objective neurological deficit accompanied by CSF pleocytosis and intrathecal antibody production to B. burgdorferi s.l. (REF. 96). In the other nine patients, clinical symptoms of CNS involvement were often vague, primarily consisting of headache, dizziness, concentration and memory disturbances and paresthesias; only two of these patients had CSF pleocytosis. Even without antibiotic therapy, acute Lyme neuroborreliosis usually improves or resolves within months ${ }^{97}$.

Acute cardiac involvement can also occur during early disseminated infection and mostly manifests as fluctuating degrees of atrioventricular nodal block, in which electrical impulses from the atria are interrupted before conduction to the ventricles. Other, less common, manifestations include acute myopericarditis or mild left ventricular dysfunction and, rarely, cardiomegaly or pancarditis ${ }^{1}$. Acute carditis usually resolves within weeks, even without antibiotic therapy. However, fatal cases have been reported ${ }^{98}$. In Europe, the spirochaete was isolated from endomyocardial biopsy samples of a patient with chronic dilated cardiomyopathy ${ }^{99}$. 


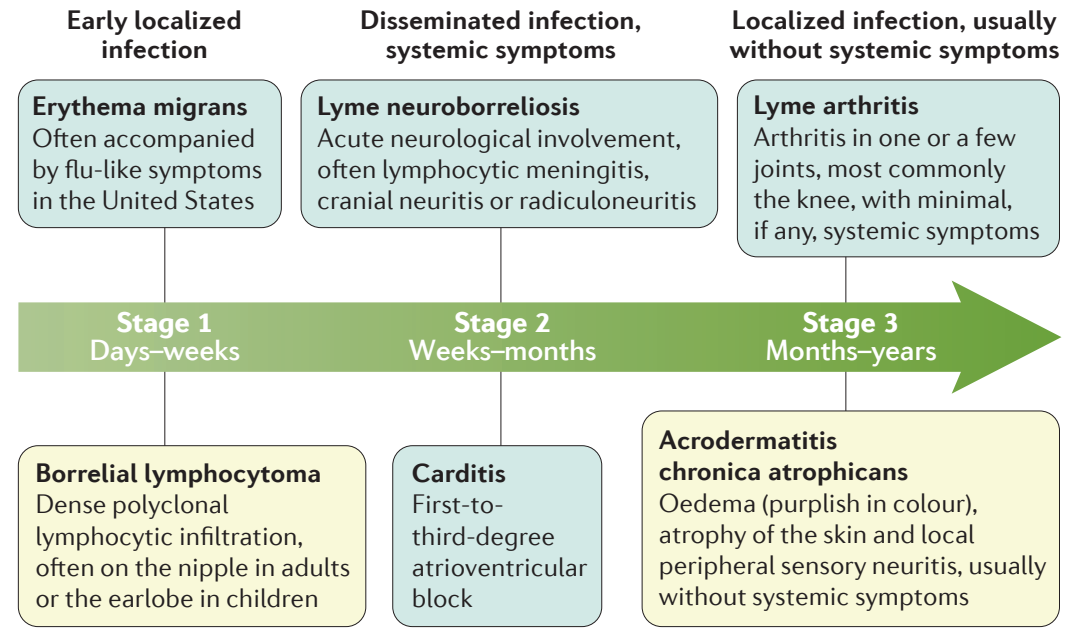

Europe

Both Europe and North America

Figure 6 | The stages and most common clinical features of Lyme borreliosis. The natural history of the infection without antibiotic therapy begins with localized infection in the skin, then dissemination of the bacteria to numerous sites, but long-term survival in only one or a few localized niches. In patients who have not been treated with antibiotics, Lyme borreliosis typically occurs in stages, with different clinical manifestations at each stage. However, the stages can overlap and late manifestations can be the presenting feature. The infection typically begins as a localized infection of the skin, but, particularly in the United States, Borrelia burgdorferi often disseminates, which is commonly associated with systemic symptoms. However, as the disease progresses and as the immune response matures, the infection typically becomes more localized, such as to the knee joint, and is accompanied by minimal, if any, systemic symptoms.

Late infection. The late, stage 3 manifestations of Lyme borreliosis in the United States diverge from those in Europe even more than the early-stage manifestations (FIG. 6). In an initial study, carried out before the cause of the disease was known, $\sim 60 \%$ of patients with erythema migrans who were not treated with antibiotics in the northeastern United States developed arthritis an average of 6 months (range: 4 days to 2 years) later ${ }^{100}$. Joint swelling and pain typically occurred in intermittent attacks primarily in large joints, especially the knee, over a period of several years, but some patients had persistent synovitis for $4-5$ years. Lyme arthritis usually resolves following appropriate oral or intravenous antibiotic therapy ${ }^{101}$. However, some patients have persistent, proliferative synovitis for months to several years, which is termed post-infectious, antibiotic-refractory Lyme arthritis ${ }^{102}$. In Europe, Lyme borreliosis can also cause arthritis, usually in one or a few large joints, but this occurs less frequently and earlier in the disease course than in the United States. In one study from Germany, the mean period from erythema migrans to the onset of arthritis was 3 months (range: 10 days to 16 months) $)^{103}$. In addition, chronic arthritis occurs rarely in Europe.

In Europe, acrodermatitis chronica atrophicans - a slowly progressive lesion that is located primarily on the extensor (acral) surfaces of the extremities - is the most frequent late manifestation of Lyme borreliosis and is more common in older women, for unclear reasons, and is rare in children ${ }^{91,104}$ (FICS 5,6). About $20 \%$ of patients with acrodermatitis chronica atrophicans have a history that is consistent with a preceding spontaneously healed erythema migrans lesion, usually on an extremity where the acrodermatitis chronica atrophicans lesion developed 6 months to 8 years later ${ }^{105}$. Acrodermatitis chronica atrophicans results primarily from B. afzelii infection, although it can also be caused by B. garinii or European B. burgdorferi infections ${ }^{106}$ and starts with an inflammatory phase that is followed by an atrophic phase, sometimes with features. The bacteria have been isolated from acrodermatitis chronica atrophicans lesions $>20$ years after its first appearance. Peripheral neuropathy and joint involvement can occur within the skin sites affected with acrodermatitis chronica atrophicans lesions.

Several rare neurological manifestations have also been associated with $B$. burgdorferi s.l. infection. In Europe, a severe neurological syndrome of chronic encephalomyelitis that is characterized by spastic paraparesis, cranial neuropathy or cognitive impairment has been described ${ }^{94}$. Stroke-like signs and symptoms in patients with Lyme borreliosis have been reported in both the United States and Europe ${ }^{107}$. In the United States, a mild, late encephalopathy that manifests primarily as subtle cognitive disturbances ${ }^{108}$ and/or a mild sensory polyneuropathy have been reported to occur ${ }^{109}$. However, the existence of these neurological syndromes is controversial and how much of the disease is due to active infection, post-infectious immune phenomena or other factors is not always clear.

\section{Diagnostic tests}

Demonstration of borrelial infection by laboratory testing is required for reliable diagnosis of Lyme borreliosis, with the exception of erythema migrans ${ }^{1,2,97,110}$. The culture of Borrelia spp. from patient specimens enables definitive diagnosis, but is generally restricted almost exclusively to research studies because of the need for special expertise and equipment. Moreover, except for patients with acrodermatitis chronica atrophicans ${ }^{104}$, positive cultures have been obtained only during the first weeks of infection, primarily from skin biopsy samples of erythema migrans lesions ${ }^{2}$. Later in the infection, PCR-based testing for B. burgdorferi DNA in synovial fluid is often positive in patients with Lyme arthritis before antibiotic therapy ${ }^{111}$, but is only positive in the CSF of a small number of patients with late Lyme neuroborreliosis. Because Borrelia DNA can persist after spirochaetal killing, PCR is not an accurate test for active infection ${ }^{111}$.

Thus, in both the United States and Europe, serological testing is the only practical and readily available method to support a diagnosis of Lyme borreliosis. In the United States, diagnosis is usually based on recognition of characteristic clinical features along with the detection of antibodies to $B$. burgdorferi, determined by enzymelinked immunosorbent assay (ELISA) and western blotting. BOX 1 summarizes the recommended approaches for serological testing for B. burgdorferi s.l. and the pitfalls to be avoided. In the United States, western blots should be interpreted according to the criteria of the Centers for Disease Control and Prevention ${ }^{112,13}$ (BOX 1). 


\section{Box 1 | Serological testing for Lyme borreliosis}

\section{Recommended approach to support diagnosis}

- Recognition of characteristic clinical manifestations

- Positive antibody response against Borrelia burgdorferi determined by a two-tiered approach of enzyme-linked immunosorbent assay (ELISA) and western blot, except in patients with erythema migrans

- In the United States, the recommended criteria from the US Centers for Disease Control and Prevention to interpret a positive western blot are:

- During the first 30 days of symptoms in a patient with early disease, at least two lgM bands of 23,39 or $41 \mathrm{kD}^{214}$

- During early or late infection, at least five lgG bands of $18,23,28,30,39,41,45,58$, 66 or $93 \mathrm{kD}^{215}$

- In Europe, there is no single set of criteria to interpret western blot results with high levels of sensitivity and specificity

- In European and North American countries, testing for antibody in cerebrospinal fluid (CSF) must be corrected for passive diffusion of anti-Borrelia antibodies from blood - Total lgG levels can be measured at both sites, adjusting the dilutions accordingly for ELISA testing ${ }^{110,216}$, or antibody capture enzyme immunoassay can be used to compare the ratio of total to specific immunoglobulin at both sites ${ }^{117}$

\section{Pitfalls to be avoided}

- Omission of first-tier ELISA and using only a second-tier western blot to support the diagnosis

- Using an IgM western blot to support a diagnosis of late Lyme borreliosis

- Using unvalidated western blot criteria

- Testing for antibody in CSF without correcting for passive diffusion of anti-Borrelia antibodies in blood

- Attributing a positive antibody response against Borrelia as an indication of persistent infection after recommended courses of antibiotic therapy, given that the anti-Borrelia antibody response (even lgM) declines slowly after antibiotic treatment and can remain positive for months or years
However, these criteria cannot be used in Europe, as no single set of interpretive criteria provides results with high sensitivity and specificity in all countries, owing to the presence of different genospecies of bacteria ${ }^{114}$. In a multicentre study to develop criteria for Europe, each laboratory identified eight bands for use in diagnosis, but no single set of criteria could be formulated ${ }^{114}$.

Serodiagnostic tests are insensitive during the first several weeks of infection when most patients with Lyme borreliosis have erythema migrans. In the United States, $20-50 \%$ of patients have positive responses, usually of the IgM isotype, during acute, early infection ${ }^{115,116}$. During the convalescent period at the end of 2-3 weeks of antibiotic treatment, $70-80 \%$ of patients have seroreactivity, still usually of the IgM isotype. However, after 4-8 weeks of untreated infection, virtually $100 \%$ of patients have IgG antibody responses.

In patients with acute Lyme neuroborreliosis, especially those with meningitis, intrathecal antibody production of IgG and IgM antibodies against Borrelia spp. can often be observed, particularly in European patients with B. garinii infection ${ }^{117}$. To demonstrate intrathecal antibody production, the testing must be corrected for the diffusion of Borrelia antibodies from the blood (BOX 1).

The major limitation of serological testing is that IgG and even IgM antibodies against $B$. burgdorferi can remain for months or years after near or complete spirochaetal elimination with antibiotics ${ }^{118}$. The amount of antibody declines slowly after treatment, but findings on western blot, which is a non-quantitative test, do not change appreciably in the post-antibiotic period. Thus, serological testing cannot be used to determine active infection or the adequacy of antibiotic therapy. Moreover, in the United States, B. burgdorferi can cause asymptomatic infections in $\sim 10 \%$ of patients ${ }^{119}$ and, in a study of seroprevalence in Sweden, $>50 \%$ of individuals who were seropositive for B. burgdorferi detected by ELISA did not remember having symptoms of Lyme borreliosis ${ }^{120}$. Thus, if patients with past or asymptomatic Borrelia infection develop another illness, particularly one with neurological or joint symptoms, the symptoms might be attributed incorrectly to Lyme borreliosis. For this reason, serological testing becomes somewhat less useful in supporting the diagnosis of current symptoms in patients with a past history of Borrelia infection.

\section{Co-infection}

In the United States, I. scapularis has been implicated in the transmission of at least five other infectious agents, most prominently Anaplasma phagocytophilum ${ }^{101}$ (previously called the agent of human granulocytic ehrlichiosis, which infects granulocytes), Babesia microti ${ }^{101}$ (a red blood cell parasite), Borrelia miyamotoi (a relapsing fever Borrelia) ${ }^{121}$ and Borrelia mayonii (a newly recognized species in the northern midwestern United States) ${ }^{122}$. Each of these agents (except that very little is currently known about $B$. mayonii infection) causes nonspecific symptoms, such as headache, myalgia, arthralgia and fatigue, with the fever being generally more prominent than in patients with Lyme borreliosis. However, chronic illness is not generally associated with these agents, although B. miyamotoi infection caused chronic meningoencephalitis in one reported immunocompromised individual ${ }^{123}$ and $B$. mayonii infection apparently caused arthritis in one of the six reported cases ${ }^{122,124}$.

A. phagocytophilum and B. microti, as well as Babesia divergens and Babesia venatorum, have been found in I. ricinus in Europe ${ }^{125,126}$. In addition, in Europe, I. ricinus can transmit tick-borne viral encephalitis ${ }^{127}$. In the United States, $\sim 0.2 \%$ of I. scapularis are infected with a related virus, called the Powassan virus (also known as the deer tick virus), but only sporadic cases of the infection have been recognized. In a small percentage of patients, particularly in older or immunocompromised patients, these neurotropic viruses can cause fatal infection ${ }^{128}$.

\section{Prevention}

Interventions for the prevention of Lyme borreliosis focus primarily on personal protective measures. Protective measures can include the avoidance of areas with high numbers of ticks, wearing protective clothing, the use of tick repellents and acaricides, checking for the presence of ticks and changing the landscape in, or nearby, residential areas to make it less habitable for ticks ${ }^{129}$. These measures have been associated with a decreased risk of infection in some studies ${ }^{130}$, 
but not in others ${ }^{131}$. Landscaping practices and the application of synthetic acaricides can substantially reduce the abundance of ticks, but might not reduce the incidence of Lyme borreliosis, which shows that the remaining ticks can still transmit the bacteria ${ }^{129}$. For individuals who are reluctant to use synthetic acaricides, entomopathogenic fungi and several compounds extracted from herbs or coniferous trees have been shown to kill or repel Ixodes spp. in field trials ${ }^{132,133}$. The frequency of the infection after an I. scapularis bite has been shown to be $1-4 \%$ in the United States ${ }^{134}$, presumably because the tick must usually be attached for $>36$ hours before transmission occurs ${ }^{135}$. However, shorter periods of tick attachment that are necessary to cause transmission have been reported for B. afzeli ${ }^{12}$. Thus, if the tick is removed quickly, then other treatments are not generally required. However, on the basis of a study conducted in the United States, one dose of doxycycline, if administered within 72 hours following a tick bite, can prevent the development of Lyme borreliosis in most individuals ${ }^{134}$.

In Europe, the frequency of clinically symptomatic infection after $I$. ricinus bites is $1-5 \%$, as in the United States. On the basis of animal studies, the transmission of Borrelia might occur in $<36$ hours with $I$. ricinus than with I. scapularis ${ }^{12}$. However, as the frequency of infected ticks tends to be less in Europe than in the United States and as the efficacy of prophylactic antibiotic therapy has not been determined there, only observation is recommended for individuals with tick bites in Europe. Vaccination for human Lyme borreliosis is not currently available in either North America or Europe.

Table 1 | Recommended treatment for adults with Lyme borreliosis

\begin{tabular}{|c|c|c|}
\hline Manifestation & Antibiotic & Treatment duration (days) \\
\hline \multirow{5}{*}{$\begin{array}{l}\text { Erythema migrans, } \\
\text { borrelial lymphocytoma or } \\
\text { acrodermatitis chronica } \\
\text { atrophicans* }\end{array}$} & Doxycycline & 10 \\
\hline & Amoxicillin & 14 \\
\hline & Cefuroxime axetil & 14 \\
\hline & Phenoxymethylpenicillin & 14 \\
\hline & Azithromycin ${ }^{\ddagger}$ & $5-10$ \\
\hline \multirow{2}{*}{$\begin{array}{l}\text { Lyme meningitis, } \\
\text { cranial neuropathy or } \\
\text { radiculopathy }\end{array}$} & Doxycycline ${ }^{\S}$ & 14 \\
\hline & Ceftriaxone ${ }^{\|}$ & 14 \\
\hline Lyme encephalomyelitis & Ceftriaxone & $14-28$ \\
\hline \multirow[t]{4}{*}{ Cardiac Lyme disease } & Doxycycline ${ }^{\S}$ & $14-21$ \\
\hline & Amoxicillin ${ }^{\S}$ & $14-21$ \\
\hline & Cefuroxime axetil ${ }^{\S}$ & $14-21$ \\
\hline & Ceftriaxonell & $14-21$ \\
\hline \multirow[t]{4}{*}{ Lyme arthritis } & Doxycycline & 28 \\
\hline & Amoxicillin & 28 \\
\hline & Cefuroxime axetil & 28 \\
\hline & Ceftriaxone" & $14-28$ \\
\hline
\end{tabular}

*Treatment duration for borrelial lymphocytoma is 14 days for $\beta$-lactam and tetracycline antibiotics; the duration for acrodermatitis chronica atrophicans is $21-28$ days. ${ }^{\ddagger}$ For patients who are unable to take $\beta$-lactams or tetracyclines. ${ }^{8}$ For ambulatory patients. "For hospitalized patients. "Used when there is only a minimal response to oral antibiotics. Adapted from the

Infectious Diseases Society of America (IDSA) treatment guidelines ${ }^{101}$ and from Sanchez et al. ${ }^{140}$.

\section{Management}

Despite differences in the B. burgdorferi s.l. genospecies that cause Lyme borreliosis in Europe and North America and the absence of studies that directly compare treatment outcomes, the overall results of antibiotic treatment seem to be remarkably similar on both continents ${ }^{97,136-138}$. Several groups have reported treatment guidelines for Lyme borreliosis, but the most comprehensive are the 2006 Infectious Diseases Society of America (IDSA) guidelines that were authored by both US and European authorities ${ }^{101}$. In 2010, the IDSA Lyme borreliosis guidelines were reviewed by an independent panel and found to be current and valid ${ }^{139}$. A recent review includes slight modifications of the IDSA guidelines ${ }^{140}$.

\section{Early localized infection}

Erythema migrans. All B. burgdorferi s.l. genospecies tested seem to be susceptible, in vitro, to tetracyclines and many $\beta$-lactam antibiotics ${ }^{101}$. No differences in the level of susceptibility among active members of these drug classes for the different genospecies that are thought to be clinically relevant have been observed and no evidence suggests the emergence of drug resistance. More variability exists among strains of Lyme borrelia with regard to the in vitro activity of certain macrolides, particularly erythromycin ${ }^{141}$. In a single study conducted in the United States, azithromycin, which is quite active in vitro, was less effective than amoxicillin in patients with erythema migrans ${ }^{142}$.

In the United States, patients with erythema migrans can usually be treated successfully with a 10-14-day course of doxycycline, amoxicillin or cefuroxime axetil $^{101,137,138,143}$ (TABLE 1). In Europe, patients can also be treated with phenoxymethylpenicillin. Patients with erythema migrans who cannot take doxycycline or $\beta$-lactam antibiotics can be treated with a 5-10-day course of azithromycin ${ }^{97,101}$. One advantage of doxycycline treatment is that it has efficacy against the rickettsial agent A. phagocytophilum, which causes human granulocytic anaplasmosis, a possible co-infection with $B$. burgdorferi s.l. However, doxycycline is intended for use in adults and adolescents and should generally be avoided in children $<8$ years of age and in women who are pregnant or breastfeeding. Although erythema migrans will resolve eventually without antibiotic therapy, treatment shortens the duration and prevents later manifestations of Lyme borreliosis $^{97,101}$ (FIG. 6).

Borrelial lymphocytoma. The antibiotic regimens used to treat erythema migrans are also highly effective for the treatment of borrelial lymphocytoma ${ }^{144}$ (TABLE 1). If untreated, borrelial lymphocytoma can last for months.

\section{Early extracutaneous disseminated infection}

Depending on the disease severity, patients with neurological or cardiac involvement of Lyme borreliosis can usually be treated successfully with the same oral antibiotics that are used for the treatment of erythema migrans (TABLE 1). However, with neurological or cardiac manifestations, a parenterally administered antibiotic might be used in certain cases. The most commonly 
prescribed parenterally administered antibiotic is ceftriaxone, as this is administered once daily, but cefotaxime and intravenous penicillin are also highly effective ${ }^{145,146}$.

Lyme neuroborreliosis. Patients who are hospitalized for Lyme-associated meningitis are typically treated with parenteral antibiotics (TABLE 1) for either a 14-day course or until they can be discharged from the hospital, at which time oral doxycycline is often substituted to complete a 14-day course of treatment. In a prospective, double-blind study in Europe, $200 \mathrm{mg}$ once-daily treatment with oral doxycycline was found to be as effective as once-daily intravenous ceftriaxone $(2 \mathrm{~g}$ ) for adults with early neurological Lyme borreliosis, with no treatment failures in either group ${ }^{147}$. Whether twice-daily administration of $100 \mathrm{mg}$ of oral doxycycline, which is perhaps better tolerated, would be equally as effective has not been studied systematically; anecdotally, twicedaily administration seems to be effective (G.P.W., unpublished observations). In patients with seventh nerve palsy, antibiotics do not lead to faster resolution of the facial weakness, but are effective in preventing later clinical sequelae, such as Lyme arthritis ${ }^{148}$. Patients with cranial neuropathy have been treated successfully with oral antibiotics other than doxycycline, including amoxicillin or cefuroxime axetil, but published data documenting the efficacy of these therapies are limited ${ }^{101}$. Encephalomyelitis, a rare neurological manifestation of Lyme borreliosis, is treated with a full course of parenteral antibiotics, although oral doxycycline has shown promising results ${ }^{149}$. No comparative trial that included an oral antibiotic has been performed in patients with Lyme encephalomyelitis.

Carditis. Cardiac manifestations commonly include varying degrees of atrioventricular block. In those with a complete (third-degree) block, hospitalization is recommended for monitoring and administration of parenteral antibiotics and patients might also need to have a temporary pacemaker implanted. Patients with advanced forms of partial heart block, including those with second-degree block or first-degree block with a PR interval of $>0.3$ seconds, should also be hospitalized for monitoring, as these patients are at risk for progression to complete heart block ${ }^{150}$. If substantial improvement allows discharge before day 14, a 2-week course of antibiotics can be completed with oral administration of any of the $\beta$-lactam or tetracycline antibiotics that are used for the treatment of erythema migrans ${ }^{140}$.

\section{Late infection}

Lyme arthritis. Lyme arthritis is typically treated with a 28-day course of an oral antibiotic ${ }^{101,151}$. Parenteral antibiotic therapy of 14-28 days in duration is reserved for patients who still have synovial inflammation following oral therapy ${ }^{101,152}$. No clinical trials have been performed comparing a 28-day course of oral antibiotic with a 14-day course of oral treatment and no clinical trials have compared the outcome of Lyme arthritis in patients treated with oral antibiotics versus parenteral therapy.
NSAIDs can be given with antibiotic therapy, but intra-articular steroids are not recommended before or during antibiotic treatment as this has the potential to result in worse outcomes, such as prolonged joint inflammation $^{145,153}$. However, prospective studies on the use of NSAIDs or intra-articular steroids are lacking. After resolution of arthritis of the knee, physical therapy might be needed if atrophy of the quadriceps has developed.

The persistence of at least mild joint inflammation immediately following antibiotic therapy is found in at least $25 \%$ of patients with Lyme arthritis, irrespective of whether intravenous ceftriaxone $e^{153}$ or an oral antibiotic ${ }^{154}$ was the initial treatment. Data from observational studies of children with Lyme arthritis indicate that the residual joint inflammation will resolve with NSAIDs and/or intra-articular injections of corticosteroids in most patients ${ }^{153,155}$. Disease-modifying anti-rheumatic drugs (DMARDs), such as methotrexate, are usually effective in those who do not respond to NSAIDs or intra-articular corticosteroids and in adults with post-antibiotic proliferative synovitis ${ }^{156}$. In responding patients, DMARDs can usually be discontinued after 6-12 months of treatment. In patients with incomplete responses, arthroscopic synovectomy is an option, but the debridement of synovial tissue down to the cartilage interface is necessary for a successful result ${ }^{156}$.

Acrodermatitis chronica atrophicans. Acrodermatitis chronica atrophicans is usually treated with a 21-28-day course of oral antibiotic therapy (TABLE 1), which can halt progression and improve or resolve the skin lesion, but not reverse the neuropathy ${ }^{106}$. If untreated, the skin lesion does not typically resolve spontaneously, and fibrosis and atrophy can develop ${ }^{104}$.

\section{Post-treatment symptoms}

In $\sim 10 \%$ of patients with erythema migrans and perhaps a higher percentage of patients with Lyme neuroborreliosis ${ }^{157-159}$, subjective symptoms such as fatigue, cognitive complaints and musculoskeletal pain can persist for $\geq 6$ months after antibiotic therapy. These symptoms have been shown to continue, at least intermittently, for $>10$ years in some cases ${ }^{157}$. In an undefined minority of patients with residual subjective symptoms following treatment of Lyme borreliosis, these symptoms are functionally disabling and are referred to as post-treatment Lyme disease syndrome (PTLDS). A proposed definition for PTLDS is the presence of subjective symptoms that begin within 6 months after the diagnosis and treatment of an objective clinical manifestation of Lyme borreliosis and persists for at least 6 months ${ }^{101}$. Whether post-treatment symptoms are more common with Lyme borreliosis than other infections, or even in healthy controls, is unknown owing to a lack of studies. In one prospective European study of patients with erythema migrans and healthy controls, the rate of new or increased symptoms at 12 months was greater in the healthy control population ${ }^{158}$.

In the United States and Europe, placebo-controlled, randomized retreatment trials using either parenteral antibiotic therapy alone or followed by a course of oral antibiotics in patients with PTLDS did not show any 
Box 2 | Therapies not recommended for Lyme borreliosis or PTLDS

- Long-term antibiotic therapy

- Multiple repeated courses of antibiotics for the same episode of Lyme borreliosis

- Combinations of antibiotics

- Pulsed dosing in which antibiotics are given on some days but not on other days

- First-generation cephalosporins, such as cephalexin, benzathine penicillin G, fluoroquinolones, carbapenems, vancomycin, metronidazole, tinidazole, trimethoprimsulfamethoxazole, amantadine, ketolides, isoniazid, rifampin or fluconazole

- Drug therapy for babesiosis (that is, a malaria-like parasitic disease) or Bartonella spp. infection in the absence of evidence for active infection

- Hyperbaric oxygen, intravenous hydrogen peroxide or ozone therapy

- Energy-based or radiation-based therapies, such as 'rife therapy'

- Nutritional therapies, such as burnt mugwort or glutathione

- Chelation and heavy-metal therapies

- Fever therapy

- Intravenous immunoglobulin

- Urotherapy (that is, the ingestion of one's own urine)

- Apheresis

- Stem cell transplantation

- Drugs (such as cholestyramine), enemas, bee venom, various hormonal therapies (such as thyroid hormone), lithium orotate, olmesartan, naltrexone or bleach

PTLDS, post-treatment Lyme disease syndrome

clinical benefit, or showed a benefit that was so modest it was outweighed by the risk of adverse effects from the treatment (for example, intravenous-line sepsis) ${ }^{160,161}$. Evidence for the persistence of infection was not found in any of these studies and a recent editorial suggests that a different approach than prolonged treatment with antibiotics for PTLDS is required ${ }^{162}$. Additional studies are needed to better understand the pathogenesis of persistent symptoms and to determine the best approaches for symptomatic relief.

Depression in patients with PTLDS should be managed as per standard practice ${ }^{163}$. Symptomatic therapy is recommended for other types of symptoms, such as joint pain. However, optimal approaches for symptomatic management have not been defined as systematic studies except those evaluating retreatment with antibiotics - are uncommon or completely lacking in these patients. Some authorities, borrowing from treatment studies of fibromyalgia, have advocated multidisciplinary approaches that combine medications, such as gabapentin or amitriptyline, with non-pharmacological therapies, for example, cognitive-behavioural therapy, acupuncture or massage ${ }^{164}$.

Many unsubstantiated therapies have been proposed for patients with Lyme borreliosis and for those patients with residual pain, neurocognitive symptoms or fatigue following treatment ${ }^{101,165}$ (BOX 2). These therapies lack proven benefit and, in some cases, pose a real risk of adverse outcomes.

\section{Quality of life}

Regardless of the disease manifestation, most patients with Lyme borreliosis respond well to antibiotic therapy and experience a complete recovery. However, some patients do not recover completely and post-infectious sequelae can affect quality of life.
In the northeastern United States, a small percentage of patients have marked proliferative synovitis that lasts for months to several years after treatment of the infection $^{102}$. Rather than persistent infection, post-infectious immune responses resulting from excessive inflammation $^{39}$, immune dysregulation ${ }^{166,167}$, infection-induced autoimmunity ${ }^{168-170}$ or retained bacterial antigens ${ }^{171}$ are thought to contribute to this. Severe and prolonged Lyme arthritis can result in premature degenerative arthritis, particularly if associated with tendon rupture or marked atrophy of the quadriceps. In a 10-20-year follow-up study in the United States, 10 of 42 patients with previous Lyme arthritis had findings that were suggestive of degenerative arthritis in previously affected knees on physical examination compared with 0 of 42 patients with previous Lyme borreliosis who did not develop Lyme arthritis $(P=0.001)^{172}$.

Long-term motor deficits can occur after Lyme neuroborreliosis. In a 10-20-year follow-up study of patients with Lyme neuroborreliosis in the United States, most of whom were seen before knowledge of antibiotic treatment for the disease, $23 \%$ of patients with facial palsy had mild-to-moderate residual deficits of facial nerve function and $26 \%$ had subtle motor or sensory peripheral nerve abnormalities ${ }^{172}$. By contrast, in a study of antibiotic-treated European patients with Bannwarth syndrome, $7 \%$ with facial palsy and $50 \%$ with motor pareses of extremities had incomplete recoveries, although only one patient had motor weakness that was functionally limiting ${ }^{95}$. Similarly, in patients with late, stage 3 Lyme neuroborreliosis, antibiotic therapy halts disease progression and patients experience substantial improvement. However, depending on the degree of parenchymal CNS involvement, recovery might be incomplete ${ }^{173}$. Risk factors for unfavourable outcomes (such as poor recovery of sensory and motor function) include female sex, pretreatment duration of symptoms of $>6$ weeks, a high CSF white blood cell count before treatment ${ }^{174,175}$ and the presence of symptoms at the end of a 14-day treatment with ceftriaxon $\mathrm{e}^{95}$. Similarly, in patients with acrodermatitis chronica atrophicans who were treated with antibiotics, the manifestations associated with long-term skin infection, such as skin atrophy, peripheral nerve abnormalities or subluxation of small joints, might improve little if at all ${ }^{104}$. Rare cases have been reported of the development of autoimmune diseases in the weeks to months after Lyme neuroborreliosis, for example, chronic idiopathic demyelinating polyneuropathy ${ }^{176}$ and cerebral vasculitis $^{177}$.

Finally, patients with post-treatment symptoms often experience improvement of their symptoms within months ${ }^{158}$, although some patients can have severe joint and muscle pain, neurocognitive difficulties and/or incapacitating fatigue that persist for years ${ }^{178}$. The pathogenesis of these symptoms is unclear and might not be the same in all patients. These symptoms might be a part of a central sensitization syndrome ${ }^{179}$ or be attributable to immune system abnormalities, for example, increased levels of IL-23 (REF. 180) or heightened levels of antineuronal antibodies ${ }^{181}$. This area is further confused as PTLDS, or what has been referred to as 'chronic Lyme 
disease', has become a diagnosis for medically unexplained symptoms, even when patients have no evidence of past or present Lyme borreliosis ${ }^{182,183}$. Importantly, the various post-infectious complications of Lyme borreliosis should not be confused with signs of persistent infection with B. burgdorferi, and prolonged antibiotic therapy has not been shown to be beneficial ${ }^{182}$.

\section{Outlook}

\section{Diagnostic tests}

In the United States, a two-tiered approach with wholecell sonicate ELISA and western blotting has worked well for serological diagnosis of Lyme borreliosis, but has limitations. Second-generation screening immunoassays have been designed using recombinant $B$. burgdorferi proteins or synthetic peptides as antigen targets ${ }^{184}$, which show an improvement in specificity compared with conventional whole-cell sonicate ELISAs. Similarly, line immunoblots or other multiplexed antibody detection platforms prepared from purified or recombinant $B$. burgdoferi proteins have been developed as a substitute for western blots ${ }^{185}$. These assays are easier to interpret and their adoption might reduce the misreading of weak bands and improve reproducibility, particularly of western blotting for IgM antibodies ${ }^{186}$. In addition, western blotting might be unnecessary in routine cases of Lyme borreliosis if two different ELISAs are used instead ${ }^{187}$. This strategy has improved sensitivity during the first weeks of infection $^{187,188}$ and reduced the costs and complexity compared with conventional two-tiered testing ${ }^{189}$. Efforts are also underway to develop rapid serological assays that can be performed in doctors' offices, so-called point-of-care tests ${ }^{190}$, which would reduce turnaround times.

Another avenue of investigation involves the measurement of biomarkers. For example, increased concentrations of CXCL13 (a chemoattractant for B cells) in CSF have been proposed as a biomarker for Lyme neuroborreliosis. Although European patients with Bannwarth syndrome typically have high levels of CXCL13 in CSF, which correlates with intrathecal antibody production against Lyme borrelia ${ }^{191,192}$, numerous other conditions can also cause increased levels of CXCL13, including neurosyphilis, HIV infection, CNS lymphoma and multiple sclerosis ${ }^{192-194}$. Thus, for use as a diagnostic test for Lyme neuroborreliosis, the cut-off concentration of CXCL13 becomes crucially important and needs definition.

Another investigative approach involves the development of proteomic, inflammatory, nucleic acid, cellular or metabolomic biosignatures of Lyme borreliosis. In one proof-of-concept study, a metabolic biosignature of 44 molecular features, such as polyunsaturated fatty acids or products of prostaglandin metabolism, correctly classified patients with early Lyme borreliosis (the majority of whom were seronegative by conventional two-tiered testing) and healthy controls with a sensitivity of $88 \%$ and a specificity of $95 \%{ }^{195}$. By contrast, in the United States, standard two-tiered testing in patients with acute erythema migrans has a sensitivity of $30 \%$ and a specificity of $99 \%$, although sensitivity rises to $60-70 \%$ with post-treatment convalescent testing ${ }^{115}$.

\section{Antibiotic treatment}

Studies on antibiotic treatment for Lyme borreliosis are relatively limited. A double-blind, placebo-controlled trial of intramuscular benzathine penicillin that started before the identification of B. burgdorferi showed the efficacy of antibiotic therapy in Lyme arthritis, but did not lead to the resolution of arthritis in all patients ${ }^{196}$. Conversely, several double-blind, placebo-controlled trials have demonstrated no benefit from additional courses of oral or intravenous antibiotic therapy in patients with PTLDS ${ }^{160}$. In addition, several randomized trials of different antibiotic regimens have been conducted on both continents in patients with erythema migrans, neuroborreliosis or Lyme arthritis. Treatment of unusual manifestations of the disease is based on case series or expert opinion. These trials are detailed in the IDSA guidelines ${ }^{101}$.

Numerous questions remain about the best approaches to treat Lyme borreliosis and well-designed studies are to be encouraged. For example, a recent retrospective analysis of patients with Lyme borreliosis and facial palsy reported a worse long-term outcome in those who received antibiotics and prednisone than in those who received antibiotics alone ${ }^{197}$. However, these regimens have not been compared in a randomized clinical trial. Another important example is the treatment of Lyme arthritis in the United States, which is currently based on an algorithm ${ }^{156}$. In formulating this step-wise approach, randomized studies of initial antibiotic therapy are available, but only case series have been published regarding patients who did not respond to oral antibiotic therapy or those who developed antibioticrefractory Lyme arthritis. Thus, any definitive study would need to compare multiple therapies and include long-term follow-up.

\section{Control of ticks or animal hosts}

Considerable research has been devoted to interventions that decrease tick abundance or interrupt the transmission of B. burgdorferi in the environment ${ }^{129}$. In areas where deer are a primary host for adult Ixodes spp., deer exclusion or population reduction has been proposed as an indirect means of tick control. Although studies on islands have suggested that deer elimination can be successful, interventions that are short of complete deer elimination have yielded mixed results ${ }^{198}$. As a possible alternative, a '4-poster' device has been developed that applies topical acaricide to deer that are drawn to a feeding station ${ }^{199}$. Several interventions designed to reduce or prevent infection among reservoir rodents are also being tested. These tools include bait boxes that treat rodents with a tick-control agent (such as fipronil), oral vaccines to immunize wild rodents against infection with $B$. burgdorferi and doxycycline hyclate-laden bait to treat and eliminate infection ${ }^{129,200}$.

Despite the theoretical promise of environmental controls, numerous obstacles exist to widespread implementation, including cost, regulatory issues and concerns over pesticide use and deer control ${ }^{201}$. Perhaps most importantly, empirical evidence demonstrating public health efficacy is lacking for most environmental interventions. Nearly all studies have focused on 
entomological outcomes, such as tick abundance, rather than human illness and most have been conducted on a small scale under optimized conditions. The importance of documenting health outcomes is highlighted by a placebo-controlled trial in which yard pesticide treatments were associated with a $60 \%$ reduction in the number of ticks, but no reduction in tick bites or tick-borne illness among household members ${ }^{202}$.

\section{Vaccination}

Although several vaccines for Lyme borreliosis are available for use in animals ${ }^{203}$, human vaccines are not available. A recombinant OspA-based vaccine was marketed in the United States from 1998 to 2002 (REF. 22), but, although safe and efficacious, this was withdrawn from the market. One important reason for this was that Lyme borreliosis advocacy groups, which initially supported the vaccine, became crucial opponents ${ }^{204}$, leading to the threat of class action lawsuits. Other reasons included vaccine cost, the need for booster vaccinations and the theoretical concern that the vaccine might trigger autoimmune arthritis ${ }^{205}$. Despite the demand for a protective vaccine for Lyme borreliosis and that vaccination is cost-effective in high-risk endemic areas ${ }^{206}$, pharmaceutical companies have subsequently been reluctant to test and market human vaccines.

Nonetheless, modified OspA-based vaccines, other spirochaetal protein-based vaccines (including one that targets BB0405 (REF. 207)) and novel delivery strategies have been the subject of investigation ${ }^{208}$. Importantly, phase I and phase II trials with a modified multivalent OspA-based vaccine that lacked a T cell epitope initially thought to have autoreactive potential, confirmed that vaccination is safe and results in robust antibody responses 209 . However, the involved pharmaceutical company is not currently moving ahead with further testing of this vaccine.

An alternative vaccination strategy to prevent Lyme borreliosis and potentially other diseases that are transmitted by the same tick would be to vaccinate against tick proteins ${ }^{208}$. This approach is based on the observation that some laboratory animals, such as guinea pigs and rabbits, when repetitively infested with ticks, develop immune responses against tick proteins, which results in impaired tick feeding and partial protection against $B$. burgdorferi ${ }^{210}$. An anti-tick vaccine against another tick species is available for the veterinary market, which underscores the feasibility of this approach $^{208}$. Finally, multiple tick saliva proteins are involved in the transmission of B. burgdorferi from the tick to the host, and targeting such proteins by vaccination has yielded partial success in experimental settings ${ }^{48,211,212}$. A new vaccine would need to meet high standards of safety, efficacy, cost and public acceptance ${ }^{213}$. Nevertheless, the feasibility of human vaccination for Lyme borreliosis has been demonstrated and vaccination could be beneficial in preventing this and other tick-borne diseases.
1. Steere, A. C. Lyme disease. N. Engl. J. Med. 321 , 586-596 (1989).

2. Steere, A. C. Lyme disease. N. Engl. J. Med. 345 115-125 (2001) This article reviews the clinical manifestations, epidemiology, pathogenesis, diagnosis and treatment of Lyme disease, with an emphasis on the correlation of clinical features with disease pathogenesis.

3. Mead, P. S. Epidemiology of Lyme disease. Infect. Dis. Clin. North Am. 29, 187-210 (2015).

This thorough review includes frequencies of Lyme borreliosis in affected countries throughout the world.

4. Hinckley, A. F. et al. Lyme disease testing by large commercial laboratories in the United States. Clin. Infect. Dis. 59, 676-681 (2014).

5. Steere, A. C. et al. Lyme arthritis: an epidemic of oligoarticular arthritis in children and adults in three connecticut communities. Arthritis Rheum. 20, 7-17 (1977).

6. Burgdorfer, W. et al. Lyme disease - a tick-borne spirochetosis? Science 216, 1317-1319 (1982).

7. Baranton, G., Assous, M. \& Postic, D. [Three bacterial species associated with Lyme borreliosis. Clinical and diagnostic implications]. Bull. Acad. Natl Med. 176 1075-1085; discussion 1085-1086 (in French) (1992).

8. Margos, G., Vollmer, S. A., Ogden, N. H. \& Fish, D. Population genetics, taxonomy, phylogeny and evolution of Borrelia burgdorferi sensu lato. Infect. Genet. Evol. 11, 1545-1563 (2011).

9. Bacon, R. M., Kugeler, K. J., Mead, P. S. \& Centers for Disease Control and Prevention (CDC). Surveillance for Lyme disease - United States, 1992-2006. MMWR Surveill. Summ. 57, 1-9 (2008).

10. Fülöp, B. \& Poggensee, G. Epidemiological situation of Lyme borreliosis in Germany: surveillance data from six eastern German States, 2002 to 2006. Parasitol. Res. 103, S117-S120 (2008).

11. Berglund, J. et al. An epidemiologic study of Lyme disease in southern Sweden. N. Engl. J. Med. 333 , 1319-1324 (1995).
12. Piesman, J. \& Gern, L. Lyme borreliosis in Europe and North America. Parasitology 129, S191-S220 (2004).

13. LoGiudice, K., Ostfeld, R. S., Schmidt, K. A. \& Keesing, F. The ecology of infectious disease: effects of host diversity and community composition on Lyme disease risk. Proc. Natl Acad. Sci. USA 100, 567-571 (2003)

14. Matuschka, F. R. \& Spielman, A. The emergence of Lyme disease in a changing environment in North America and central Europe. Exp. Appl. Acarol. 2 , 337-353 (1986)

15. Rand, P. W. et al. Deer density and the abundance of Ixodes scapularis (Acari: Ixodidae). J. Med. Entomol. 40, 179-184 (2003).

16. Gern, L. Life cycle of Borrelia burgdorferi sensu lato and transmission to humans. Curr. Probl. Dermatol. 37, 18-30 (2009)

17. Ogden, N. H. et al. Role of migratory birds in introduction and range expansion of Ixodes scapularis ticks and of Borrelia burgdorferi and Anaplasma phagocytophilum in Canada. Appl. Environ. Microbiol. 74, 1780-1790 (2008)

18. Hubálek, Z. Epidemiology of Lyme borreliosis. Curr. Probl. Dermatol. 37, 31-50 (2009)

19. Ai, C. X., Zhang, W. F. \& Zhao, J. H. Sero-epidemiology of Lyme disease in an endemic area in China. Microbiol. Immunol. 38, 505-509 (1994).

20. Kugeler, K. J., Farley, G. M., Forrester, J. D. \& Mead, P. S. Geographic distribution and expansion of human Lyme disease, United States. Emerg. Infect. Dis. 21, 1455-1457 (2015).

21. Public Health Agency of Canada. Canada Communicable Disease Report (CCDR) Vol. 40-45 (2014)

22. Steere, A. C. et al. Vaccination against Lyme disease with recombinant Borrelia burgdorferi outer-surface lipoprotein A with adjuvant. Lyme Disease Vaccine Study Group. N. Engl. J. Med. 339, 209-215 (1998)

23. Richard, S. \& Oppliger, A. Zoonotic occupational diseases in forestry workers - Lyme borreliosis, tularemia and leptospirosis in Europe. Ann. Agr. Environ. Med. 22, 43-50 (2015).
24. Wilking, H., Fingerle, V., Klier, C., Thamm, M. \& Stark, K. Antibodies against Borrelia burgdorferi sensu lato among adults, Germany, 2008-2011. Emerg. Infect. Dis. 21, 107-110 (2015).

25. Orloski, K. A. et al. Emergence of Lyme disease in Hunterdon County, New Jersey, 1993: a casecontrol study of risk factors and evaluation of reporting patterns. Am. J. Epidemiol. 147, 391-397 (1998).

26. Charon, N. W. et al. The unique paradigm of spirochete motility and chemotaxis. Annu. Rev. Microbiol. 66, 349-370 (2012).

27. Xu, H., Raddi, G., Liu, J., Charon, N. W. \& Li, C. Chemoreceptors and flagellar motors are subterminally located in close proximity at the two cell poles in spirochetes. J. Bacteriol. 193, 2652-2656 (2011).

28. Bakker, R. G., Li, C., Miller, M. R., Cunningham, C. \& Charon, N. W. Identification of specific chemoattractants and genetic complementation of a Borrelia burgdorferi chemotaxis mutant: flow cytometry-based capillary tube chemotaxis assay. Appl. Environ. Microbiol. 73, 1180-1188 (2007).

29. Shi, W., Yang, Z., Geng, Y., Wolinsky, L. E. \& Lovett, M. A. Chemotaxis in Borrelia burgdorferi. J. Bacteriol. 180, 231-235 (1998)

30. Stübs, G. et al. Acylated cholesteryl galactosides are specific antigens of borrelia causing Lyme disease and frequently induce antibodies in late stages of disease. J. Biol. Chem. 284, 13326-13334 (2009).

31. LaRocca, T. J. et al. Cholesterol lipids of Borrelia burgdorferi form lipid rafts and are required for the bactericidal activity of a complement-independent antibody. Cell Host Microbe 8, 331-342 (2010).

32. Samuels, D. S. Gene regulation in Borrelia burgdorferi. Annu. Rev. Microbiol. 65, 479-499 (2011).

33. Radolf, J. D., Caimano, M. J., Stevenson, B. \& Hu, L. T. Of ticks, mice and men: understanding the dual-host lifestyle of Lyme disease spirochaetes. Nat. Rev. Microbiol. 10, 87-99 (2012).

34. Zückert, W. R. A call to order at the spirochaetal hostpathogen interface. Mol. Microbiol. 89, 207-211 (2013). 
35. Fraser, C. M. et al. Genomic sequence of a Lyme disease spirochaete, Borrelia burgdorferi. Nature 390, 580-586 (1997)

36. Casjens, S. et al. A bacterial genome in flux: the twelve linear and nine circular extrachromosomal DNAs in an infectious isolate of the Lyme disease spirochete Borrelia burgdorferi. Mol. Microbiol. 35, 490-516 (2000).

37. Wormser, G. P. et al. Borrelia burgdorferi genotype predicts the capacity for hematogenous dissemination during early Lyme disease. J. Infect. Dis. 198, 1358-1364 (2008).

38. Jones, K. L., McHugh, G. A., Glickstein, L. J. \& Steere, A. C. Analysis of Borrelia burgdorferi genotypes in patients with Lyme arthritis: high frequency of ribosomal RNA intergenic spacer type 1 strains in antibiotic-refractory arthritis. Arthritis Rheum. 60, 2174-2182 (2009)

39. Strle, K., Shin, J. J., Glickstein, L. J. \& Steere, A. C. Association of a Toll-like receptor 1 polymorphism with heightened Th1 inflammatory responses and antibiotic-refractory Lyme arthritis. Arthritis Rheum. 64, 1497-1507 (2012)

This study demonstrates that the combination of spirochaetal and host genetics, in this case infection with an RST1 strain in patients with a TLR1 polymorphism (1805GG), leads to greater inflammation, more-severe early disease and a greater frequency of antibiotic-refractory Lyme arthritis.

40. Corona, A. \& Schwartz, I. Borrelia burgdorferi: carbon metabolism and the tick-mammal enzootic cycle. Microbiol. Spectr. 3, MBP-0011-2014 (2015).

41. Johnson, R. C. The spirochetes. Annu. Rev. Microbiol. 31, 89-106 (1977)

42. Crowley, J. T. et al. Lipid exchange between Borrelia burgdorferi and host cells. PLoS Pathog. 9, e1003109 (2013).

43. Hübner, A. et al. Expression of Borrelia burgdorferi OspC and $\mathrm{DbpA}$ is controlled by a RpoN-RpoS regulatory pathway. Proc. Natl Acad. Sci. USA 98, 12724-12729 (2001)

44. Wang, P. et al. Borrelia burgdorferi oxidative stress regulator BosR directly represses lipoproteins primarily expressed in the tick during mammalian infection. Mol. Microbiol. 89, 1140-1153 (2013).

45. Pal, U. et al. TROSPA, an Ixodes scapularis receptor for Borrelia burgdorferi. Cell 119, 457-468 (2004).

46. Grimm, D. et al. Outer-surface protein C of the Lyme disease spirochete: a protein induced in ticks for infection of mammals. Proc. Natl Acad. Sci. USA 101 3142-3147 (2004)

47. Hovius, J. W. R., Levi, M. \& Fikrig, E. Salivating for knowledge: potential pharmacological agents in tick saliva. PLoS Med. 5, e43 (2008)

48. Ramamoorthi, N. et al. The Lyme disease agent exploits a tick protein to infect the mammalian host. Nature 436, 573-577 (2005)

49. Coburn, J., Leong, J. \& Chaconas, G. Illuminating the roles of the Borrelia burgdorferi adhesins. Trends Microbiol. 21, 372-379 (2013)

50. Brissette, C. A. \& Gaultney, R. A. That's my story, and I'm sticking to it - an update on B. burgdorfer adhesins. Front. Cell. Infect. Microbiol. 4, 41 (2014).

51. Moriarty, T. J. et al. Vascular binding of a pathogen under shear force through mechanistically distinct sequential interactions with host macromolecules. Mol. Microbiol. 86, 1116-1131 (2012)

52. de Taeye, S. W., Kreuk, L., van Dam, A. P., Hovius, J. W. \& Schuijt, T. J. Complement evasion by Borrelia burgdorferi: it takes three to tango. Trends Parasitol. 29, 119-128 (2013)

53. Kraiczy, P. \& Stevenson, B. Complement regulatoracquiring surface proteins of Borrelia burgdorferi structure, function and regulation of gene expression. Ticks Tick Borne. Dis. 4, 26-34 (2013).

54. Zhang, J. R., Hardham, J. M., Barbour, A. G. \& Norris, S. J. Antigenic variation in Lyme disease borreliae by promiscuous recombination of VMP-like sequence cassettes. Cell 89, 275-285 (1997).

55. Rogovskyy, A. S. \& Bankhead, T. Variable VIsE is critical for host reinfection by the Lyme disease spirochete. PLOS ONE 8, e61226 (2013).

56. Duray, P. H. Histopathology of clinical phases of human Lyme disease. Rheum. Dis. Clin. North Am. 15 691-710 (1989).

57. Müllegger, R. R. et al. Differential expression of cytokine mRNA in skin specimens from patients with erythema migrans or acrodermatitis chronica atrophicans. J. Invest. Dermatol. 115, 1115-1123 (2000).
58. Jones, K. L. et al. Higher mRNA levels of chemokines and cytokines associated with macrophage activation in erythema migrans skin lesions in patients from the United States than in patients from Austria with Lyme borreliosis. Clin. Infect. Dis. 46, 85-92 (2008).

59. Salazar, J. C. et al. Coevolution of markers of innate and adaptive immunity in skin and peripheral blood of patients with erythema migrans. J. Immunol. 171 , 2660-2670 (2003)

60. Müllegger, R. R. et al. Chemokine signatures in the skin disorders of Lyme borreliosis in Europe: predominance of CXCL9 and CXCL10 in erythema migrans and acrodermatitis and CXCL13 in lymphocytoma. Infect. Immun. 75, 4621-4628 (2007).

61. Philipp, M. T. et al. Early and early disseminated phases of Lyme disease in the rhesus monkey: a model for infection in humans. Infect. Immun. 61, 3047-3059 (1993)

62. Xu, Q., Seemanapalli, S. V., Reif, K. E., Brown, C. R. \& Liang, F. T. Increasing the recruitment of neutrophils to the site of infection dramatically attenuates Borrelia burgdorferi infectivity. J. Immunol. 178, 5109-5115 (2007).

63. Sjöwall, J. et al. Decreased Th1-type inflammatory cytokine expression in the skin is associated with persisting symptoms after treatment of erythema migrans. PLoS ONE 6, e18220 (2011).

64. Lazarus, J. J., Meadows, M. J., Lintner, R. E. \& Wooten, R. M. IL-10 deficiency promotes increased Borrelia burgdorferi clearance predominantly through enhanced innate immune responses. J. Immunol. 177, 7076-7085 (2006)

65. Salazar, J. C. et al. Activation of human monocytes by live Borrelia burgdorferi generates TLR2-dependent and -independent responses which include induction of IFN- $\beta$. PLoS Pathog. 5, e1000444 (2009).

66. Hirschfeld, M. et al. Cutting edge: inflammatory signaling by Borrelia burgdorferi lipoproteins is mediated by Toll-like receptor 2. J. Immunol. 163 2382-2386 (1999).

67. Lien, E. et al. Toll-like receptor 2 functions as a pattern recognition receptor for diverse bacterial products. J. Biol. Chem. 274, 33419-33425 (1999).

68. Shin, O. S. et al. Distinct roles for MyD88 and Toll-like receptors 2, 5, and 9 in phagocytosis of Borrelia burgdorferi and cytokine induction. Infect. Immun. 76 2341-2351 (2008)

69. Petzke, M. M., Brooks, A., Krupna, M. A., Mordue, D. \& Schwartz, I. Recognition of Borrelia burgdorferi, the Lyme disease spirochete, by TLR7 and TLR9 induces a type I IFN response by human immune cells. J. Immunol. 183, 5279-5292 (2009)

70. Cervantes, J. L. et al. Phagosomal signaling by Borrelia burgdorferi in human monocytes involves Toll-like receptor (TLR) 2 and TLR8 cooperativity and TLR8-mediated induction of IFN- $\beta$. Proc. Natl Acad. Sci. USA 108, 3683-3688 (2011)

71. Hu, L. T. et al. Host metalloproteinases in Lyme arthritis. Arthritis Rheum. 44, 1401-1410 (2001).

72. Wooten, R. M. et al. Toll-like receptor 2 is required for innate, but not acquired, host defense to Borrelia burgdorferi. J. Immunol. 168, 348-355 (2002).

73. Liu, N., Montgomery, R. R., Barthold, S. W. $\delta$ Bockenstedt, L. K. Myeloid differentiation antigen 88 deficiency impairs pathogen clearance but does not alter inflammation in Borrelia burgdorferi-infected mice. Infect. Immun. 72, 3195-3203 (2004).

74. Bolz, D. D. et al. MyD88 plays a unique role in host defense but not arthritis development in Lyme disease. J. Immunol. 173, 2003-2010 (2004).

75. Behera, A. K. et al. MyD88 deficiency results in tissue-specific changes in cytokine induction and inflammation in interleukin-18-independent mice infected with Borrelia burgdorferi. Infect. Immun. 74 1462-1470 (2006)

76. Petnicki-Ocwieja, T. et al. TRIF mediates Toll-like receptor 2-dependent inflammatory responses to Borrelia burgdorferi. Infect. Immun. 81, 402-410 (2013)

77. Petnicki-Ocwieja, T. et al. Nod2 suppresses Borrelia burgdorferi mediated murine Lyme arthritis and carditis through the induction of tolerance. PLOS ONE 6, e17414 (2011)

78. Benhnia, M. R.-E.-1, et al. Signaling through CD14 attenuates the inflammatory response to Borrelia burgdorferi, the agent of Lyme disease. J. Immunol. 174, 1539-1548 (2005).

79. Dennis, V. A., Jefferson, A., Singh, S. R., Ganapamo, F. \& Philipp, M. T. Interleukin-10 anti-inflammatory response to Borrelia burgdorferi, the agent of Lyme disease: a possible role for suppressors of cytokine signaling 1 and 3. Infect. Immun. 74, 5780-5789 (2006).

80. Sahay, B. et al. CD14 signaling restrains chronic inflammation through induction of p38-MAPK/SOCSdependent tolerance. PLoS Pathog. 5, e1000687 (2009).

81. Duray, P. H. The surgical pathology of human Lyme disease. An enlarging picture. Am. J. Surg. Pathol. 11 (Suppl. 1), 47-60 (1987).

82. Barthold, S. W., Beck, D. S., Hansen, G. M., Terwilliger, G. A. \& Moody, K. D. Lyme borreliosis in selected strains and ages of laboratory mice. J. Infect. Dis. 162, 133-138 (1990).

83. Steere, A. C. \& Glickstein, L. Elucidation of Lyme arthritis. Nat. Rev. Immunol. 4, 143-152 (2004).

84. Kinjo, Y. et al. Natural killer T cells recognize diacylglycerol antigens from pathogenic bacteria. Nat. Immunol. 7, 978-986 (2006).

85. Oliver, A. M., Martin, F., Gartland, G. L., Carter, R. H. \& Kearney, J. F. Marginal zone B cells exhibit unique activation, proliferative and immunoglobulin secretory responses. Eur. J. Immunol. 27, 2366-2374 (1997).

86. Wormser, G. P. Clinical practice. Early Lyme disease. N. Engl. J. Med. 354, 2794-2801 (2006).

87. Steere, A. C. \& Sikand, V. K. The presenting manifestations of Lyme disease and the outcomes of treatment. N. Engl. J. Med. 348, 2472-2474 (2003)

88. Cerar, T. et al. Differences in genotype, clinical features, and inflammatory potential of Borrelia burgdorferi sensu stricto strains from Europe and the United States. Emerg. Infect. Dis. 22, 818-827 (2016).

89. Strle, F. et al. Comparison of culture-confirmed erythema migrans caused by Borrelia burgdorferi sensu stricto in New York state and by Borrelia afzelii in Slovenia. Ann. Intern. Med. 130, 32-36 (1999).

90. Strle, F. et al. Comparison of erythema migrans caused by Borrelia burgdorferi and Borrelia garinii. Vector Borne Zoonotic Dis. 11, 1253-1258 (2011).

91. Mullegger, R. R. Dermatological manifestations of Lyme borreliosis. Eur. J. Dermatol. 14, 296-309 (2004).

92. Pachner, A. R. \& Steere, A. C. The triad of neurologic manifestations of Lyme disease: meningitis, cranial neuritis, and radiculoneuritis. Neurology 35, 47-53 (1985).

93. Vallat, J. M. et al. Tick-bite meningoradiculoneuritis: clinical, electrophysiologic, and histologic findings in 10 cases. Neurology 37, 749-753 (1987).

94. Oschmann, P. et al. Stages and syndromes of neuroborreliosis. J. Neurol. 245, 262-272 (1998). This case series describes the frequency and clinical characteristics of the different early and late neurological syndromes that are associated with Lyme neuroborreliosis in Europe.

95. Ogrinc, K. et al. Course and outcome of early European Lyme neuroborreliosis (Bannwarth syndrome): clinical and laboratory findings. Clin. Infect. Dis. 63, 346-353 (2016).

96. Strle, F., Ruzić-Sabljič, E., Cimperman, J., Lotric-Furlan, S. \& Maraspin, V. Comparison of findings for patients with Borrelia garinii and Borrelia afzelii isolated from cerebrospinal fluid. Clin. Infect. Dis. 43, 704-710 (2006).

97. Stanek, G., Wormser, G. P., Gray, J. \& Strle, F. Lyme borreliosis. Lancet 379, 461-473 (2012).

98. Centers for Disease Control and Prevention (CDC). Three sudden cardiac deaths associated with Lyme carditis - United States, November 2012-July 2013. MMWR Morb. Mortal. Wkly Rep. 62, 993-996 (2013)

99. Stanek, G., Klein, J., Bittner, R. \& Glogar, D. Isolation of Borrelia burgdorferi from the myocardium of a patient with longstanding cardiomyopathy. N. Engl. J. Med. 322, 249-252 (1990).

100. Steere, A. C., Schoen, R. T. \& Taylor, E. The clinical evolution of Lyme arthritis. Ann. Intern. Med. 107, 725-731 (1987)

101. Wormser, G. P. et al. The clinical assessment, treatment, and prevention of Lyme disease, human granulocytic anaplasmosis, and babesiosis: clinical practice guidelines by the Infectious Diseases Society of America. Clin. Infect. Dis. 43, 1089-1134 (2006). This comprehensive review details the treatment studies for Lyme borreliosis and provides guidelines for the treatment of the infection.

102. Steere, A. C. \& Angelis, S. M. Therapy for Lyme arthritis: strategies for the treatment of antibiotic refractory arthritis. Arthritis Rheum. 54, 3079-3086 (2006). 
103. Herzer, P. Joint manifestations of Lyme borreliosis in Europe. Scand. J. Infect. Dis. Suppl. 77, 55-63 (1991).

104. Asbrink, E., Brehmer-Andersson, E. \& Hovmark, A. Acrodermatitis chronica atrophicans a spirochetosis. Clinical and histopathological picture based on 32 patients; course and relationship to erythema chronicum migrans Afzelius. Am J. Dermatopathol. 8, 209-219 (1986).

105. Asbrink, E., Hovmark, A. \& Olsson, I. Clinical manifestations of acrodermatitis chronica atrophicans in 50 Swedish patients. Zentralbl. Bakteriol. Mikrobiol. Hyg. A 263, 253-261 (1986).

106. Lipsker, D. \& Jaulhac, B. (eds) Lyme Borreliosis (S. Karger AG, 2009)

107. Reik, L. Stroke due to Lyme disease. Neurology 43 2705-2707 (1993).

108. Halperin, J. J. Nervous system Lyme disease. J. Neurol. Sci. 153, 182-191 (1998)

109. Logigian, E. L. Peripheral nervous system Lyme borreliosis. Semin. Neurol 17, 25-30 (1997)

110. Stanek, G. et al. Lyme borreliosis: clinical case definitions for diagnosis and management in Europe. Clin. Microbiol. Infect. 17, 69-79 (2011).

111. Li, X. et al. Burden and viability of Borrelia burgdorferi in skin and joints of patients with erythema migrans or Lyme arthritis. Arthritis Rheum. 63, 2238-2247 (2011).

112. Wharton, M., Chorba, T. L., Vogt, R. L., Morse, D. L. \& Buehler, J. W. Case definitions for public health surveillance. MMWR Recomm. Rep. 39, 1-43 (1990).

113. Centers for Disease Control and Prevention (CDC) Recommendations for test performance and interpretation from the Second National Conference on Serologic Diagnosis of Lyme Disease. MMWR Morb. Mortal. Wkly Rep. 44, 590-591 (1995).

114. Hauser, U., Lehnert, G. \& Wilske, B. Validity of interpretation criteria for standardized western blots (immunoblots) for serodiagnosis of Lyme borreliosis based on sera collected throughout Europe. J. Clin. Microbiol. 37, 2241-2247 (1999).

115. Steere, A. C., McHugh, G., Damle, N. \& Sikand, V. K. Prospective study of serologic tests for Lyme disease. Clin. Infect. Dis. 47, 188-195 (2008)

116. Leeflang, M. M. G. et al. The diagnostic accuracy of serological tests for Lyme borreliosis in Europe: a systematic review and meta-analysis. BMC Infect. Dis. 16, 140 (2016).

117. Steere, A. C. Berardi, V. P., Weeks, K. E., Logigian, E. L. \& Ackermann, R. Evaluation of the intrathecal antibody response to Borrelia burgdorferi as a diagnostic test for Lyme neuroborreliosis. J. Infect. Dis. 161, 1203-1209 (1990).

118. Kalish, R. A. et al. Persistence of immunoglobulin M or immunoglobulin $\mathrm{G}$ antibody responses to Borrelia burgdorferi 10-20 years after active Lyme disease. Clin. Infect. Dis. 33, 780-785 (2001)

119. Steere, A. C., Sikand, V. K., Schoen, R. T. \& Nowakowski, J. Asymptomatic infection with Borrelia burgdorferi. Clin. Infect. Dis. 37, 528-532 (2003).

120. Gustafson, R., Svenungsson, B., Forsgren, M., Gardulf, A. \& Granström, M. Two-year survey of the incidence of Lyme borreliosis and tick-borne encephalitis in a high-risk population in Sweden. Eur. J. Clin. Microbiol. Infect. Dis. 11, 894-900 (1992).

121. Molloy, P. J. et al. Borrelia miyamotoi disease in the northeastern United States: a case series. Ann. Intern. Med. 163, 91-98 (2015)

122. Pritt, B. S. et al. Borrelia mayonii sp. nov., a member of the Borrelia burgdorferi sensu lato complex, detected in patients and ticks in the upper midwestern United States. Int. J. Syst. Evol. Microbiol. http://dx. doi.org/10.1099/ijsem.0.001445 (2016).

123. Gugliotta, J. L., Goethert, H. K., Berardi, V. P. \& Telford, S. R. Meningoencephalitis from Borrelia miyamotoi in an immunocompromised patient. N. Engl. J. Med. 368, 240-245 (2013).

124. Pritt, B. S. \& Petersen, J. M. Borrelia mayonii: prying open Pandora's box of spirochetes - authors' reply. Lancet Infect. Dis. 16, 637-638 (2016).

125. Strle, F. Human granulocytic ehrlichiosis in Europe. Int J. Med. Microbiol. 293 (Suppl. 37), 27-35 (2004).

126. Michelet, L. et al. High-throughput screening of tickborne pathogens in Europe. Front. Cell. Infect. Microbiol. 4, 103 (2014).

127. Lindquist, L. \& Vapalahti, O. Tick-borne encephalitis. Lancet 371, 1861-1871 (2008)

128. Tavakoli, N. P. et al. Fatal case of deer tick virus encephalitis. N. Engl. J. Med. 360, 2099-2107 (2009).
129. Hayes, E. B. \& Piesman, J. How can we prevent Lyme disease? N. Engl. J. Med. 348, 2424-2430 (2003).

130. Connally, N. P. et al. Peridomestic Lyme disease prevention: results of a population-based case-control study. Am. J. Prev. Med. 37, 201-206 (2009).

131. Văzquez, M. et al. Effectiveness of personal protective measures to prevent Lyme disease. Emerg. Infect. Dis. 14, 210-216 (2008)

132. Dolan, M. C. \& Panella, N. A. in Recent Developments in Invertebrate Repellents (eds Paluch, G. E. \& Coats, J. R.) 1-19 (American Chemical Society, 2011).

133. Rand, P. W. et al. Trial of a minimal-risk botanical compound to control the vector tick of Lyme disease. J. Med. Entomol. 47, 695-698 (2010)

134. Nadelman, R. B. et al. Prophylaxis with single-dose doxycycline for the prevention of Lyme disease after an Ixodes scapularis tick bite. N. Engl. J. Med. 345 , 79-84 (2001).

135. Piesman, J. Dynamics of Borrelia burgdorferi transmission by nymphal Ixodes dammini ticks. J. Infect. Dis. 167, 1082-1085 (1993).

136. Halperin, J. J. et al. Practice parameter: treatment of nervous system Lyme disease (an evidence-based review): report of the Quality Standards Subcommittee of the American Academy of Neurology. Neurology 69, 91-102 (2007)

137. Stupica, D., Lusa, L., Ruzič-Sabljić, E., Cerar, T. \& Strle, F. Treatment of erythema migrans with doxycycline for 10 days versus 15 days. Clin. Infect. Dis. 55, 343-350 (2012).

138. Wormser, G. P. et al. Duration of antibiotic therapy for early Lyme disease. A randomized, double-blind, placebo-controlled trial. Ann. Intern. Med. 138 697-704 (2003)

139. Lantos, P. M. et al. Final report of the Lyme disease review panel of the Infectious Diseases Society of America. Clin. Infect. Dis. 51, 1-5 (2010)

140. Sanchez, E., Vannier, E., Wormser, G. P. \& Hu, L. T. Diagnosis, treatment, and prevention of Lyme disease, human granulocytic anaplasmosis, and babesiosis: a review. JAMA 315, 1767-1777 (2016)

141. Terekhova, D., Sartakova, M. L., Wormser, G. P., Schwartz, I. \& Cabello, F. C. Erythromycin resistance in Borrelia burgdorferi. Antimicrob. Agents Chemother 46, 3637-3640 (2002)

142. Luft, B. J. et al. Azithromycin compared with amoxicillin in the treatment of erythema migrans. A double-blind, randomized, controlled trial. Ann. Intern. Med. 124, 785-791 (1996)

143. Kowalski, T. J., Tata, S., Berth, W., Mathiason, M. A. \& Agger, W. A. Antibiotic treatment duration and longterm outcomes of patients with early Lyme disease from a Lyme disease-hyperendemic area. Clin. Infect Dis. 50, 512-520 (2010)

144. Strle, F. et al. Treatment of borrelial lymphocytoma. Infection 24, 80-84 (1996).

145. Dattwyler, R. J., Halperin, J. J., Volkman, D. J. ¿ Luft, B. J. Treatment of late Lyme borreliosis randomised comparison of ceftriaxone and penicillin. Lancet 1, 1191-1194 (1988).

146. Hassler, D. et al. Cefotaxime versus penicillin in the late stage of Lyme disease - prospective, randomized therapeutic study. Infection 18, 16-20 (1990).

147. Ljøstad, U. et al. Oral doxycycline versus intravenous ceftriaxone for European Lyme neuroborreliosis: a multicentre, non-inferiority, double-blind, randomised trial. Lancet Neurol. 7, 690-695 (2008).

148. Clark, J. R., Carlson, R. D., Sasaki, C. T., Pachner, A. R. \& Steere, A. C. Facial paralysis in Lyme disease. Laryngoscope 95, 1341-1345 (1985).

149. Bremell, D. \& Dotevall, L. Oral doxycycline for Lyme neuroborreliosis with symptoms of encephalitis, myelitis, vasculitis or intracranial hypertension. Eur. J. Neurol. 21, 1162-1167 (2014).

150. Steere, A. C. et al. Lyme carditis: cardiac abnormalities of Lyme disease. Ann. Intern. Med. 93, 8-16 (1980).

151. Tory, H. O., Zurakowski, D. \& Sundel, R. P. Outcomes of children treated for Lyme arthritis: results of a large pediatric cohort. J. Rheumatol. 37, 1049-1055 (2010).

152. Dattwyler, R. J. et al. A comparison of two treatment regimens of ceftriaxone in late Lyme disease. Wien. Klin. Wochenschr. 117, 393-397 (2005)

153. Bentas, W., Karch, H. \& Huppertz, H. I. Lyme arthritis in children and adolescents: outcome 12 months after initiation of antibiotic therapy. J. Rheumatol. 27, 2025-2030 (2000)

154. Wormser, G. P., Nadelman, R. B. \& Schwartz, The amber theory of Lyme arthritis: initial description and clinical implications. Clin. Rheumatol. 31 989-994 (2012).
155. Nimmrich, S., Becker, I. \& Horneff, G. Intraarticular corticosteroids in refractory childhood Lyme arthritis. Rheumatol. Int. 34, 987-994 (2014).

156. Arvikar, S. L. \& Steere, A. C. Diagnosis and treatment of Lyme arthritis. Infect. Dis. Clin. North Am. 29, 269-280 (2015)

157. Weitzner, E. et al. Long-term assessment of posttreatment symptoms in patients with cultureconfirmed early Lyme disease. Clin. Infect. Dis. 61 1800-1806 (2015).

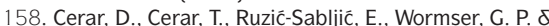 Strle, F. Subjective symptoms after treatment of early Lyme disease. Am. J. Med. 123, 79-86 (2010)

159. Vrethem, M. et al. Chronic symptoms are common in patients with neuroborreliosis - a questionnaire follow-up study. Acta Neurol. Scand. 106, 205-208 (2002).

160. Klempner, M. S. et al. Treatment trials for post-Lyme disease symptoms revisited. Am. J. Med. 126, 665-669 (2013).

This article reviews the results of four double-blind, placebo-controlled trials in which patients with post-Lyme disease symptoms were treated with additional antibiotic therapy or placebo; none of the trials showed significant differences between the groups or benefit so marginal as to be outweighed by the potential for adverse effects of the antibiotics.

161. Berende, A. et al. Randomized trial of longer-term therapy for symptoms attributed to Lyme disease N. Engl. J. Med. 374, 1209-1220 (2016)

162. Melia, M. T. \& Auwaerter, P. G. Time for a different approach to Lyme disease and long-term symptoms N. Engl. J. Med. 374, 1277-1278 (2016)

163. Hassett, A. L., Radvanski, D. C., Buyske, S Savage, S. V. \& Sigal, L. H. Psychiatric comorbidity and other psychological factors in patients with "chronic Lyme disease". Am. J. Med. 122, 843-850 (2009).

164. Steere, A. C. \& Arvikar, S. L. Editorial commentary: what constitutes appropriate treatment of post-Lyme disease symptoms and other pain and fatigue syndromes? Clin. Infect. Dis. 60, 1783-1785 (2015).

165. Lantos, P. M. et al. Unorthodox alternative therapies marketed to treat Lyme disease. Clin. Infect. Dis. 60 . 1776-1782 (2015).

166. Shen, S. et al. Treg cell numbers and function in patients with antibiotic-refractory or antibiotic responsive Lyme arthritis. Arthritis Rheum. 62 2127-2137 (2010)

167. Vudattu, N. K., Strle, K., Steere, A. C. \& Drouin, E. E. Dysregulation of CD4 + CD2 $5^{\text {high }} \mathrm{T}$ cells in the synovial fluid of patients with antibiotic-refractory Lyme arthritis. Arthritis Rheum. 65, 1643-1653 (2013).

168. Drouin, E. E. et al. A novel human autoantigen, endothelial cell growth factor, is a target of $\mathrm{T}$ and $\mathrm{B}$ cell responses in patients with Lyme disease. Arthritis Rheum. 65, 186-196 (2013).

169. Crowley, J. T. et al. A highly expressed human protein apolipoprotein B-100, serves as an autoantigen in a subgroup of patients with Lyme disease. J. Infect. Dis. 212, 1841-1850 (2015).

170. Crowley, J. T. et al. Matrix metalloproteinase-10 is a target of $\mathrm{T}$ and $\mathrm{B}$ cell responses that correlate with synovial pathology in patients with antibioticrefractory Lyme arthritis. J. Autoimmun. 69, 24-37 (2016).

171. Bockenstedt, L. K., Gonzalez, D. G., Haberman, A. M. $\&$ Belperron, A. A. Spirochete antigens persist near cartilage after murine Lyme borreliosis therapy. J. Clin. Invest. 122, 2652-2660 (2012).

172. Kalish, R. A. et al. Evaluation of study patients with Lyme disease, 10-20-year follow-up. J. Infect. Dis. 183, 453-460 (2001).

173. Hansen, K., Crone, C. \& Kristoferitsch, W. Lyme neuroborreliosis. Handb. Clin. Neurol. 115, 559-575 (2013).

174. Ljøstad, U. \& Mygland, A. Remaining complaints 1 year after treatment for acute Lyme neuroborreliosis; frequency, pattern and risk factors. Eur. J. Neurol. 17, 118-123 (2010).

175. Eikeland, R., Mygland, Å., Herlofson, K. \& Ljøstad, U. Risk factors for a non-favorable outcome after treated European neuroborreliosis. Acta Neurol. Scand. 127, 154-160 (2013)

176. Rupprecht, T. A., Elstner, M., Weil, S. \& Pfister, H.-W. Autoimmune-mediated polyneuropathy triggered by borrelial infection? Muscle Nerve 37, 781-785 (2008).

177. Hemmer, B. et al. Identification of candidate T-cell epitopes and molecular mimics in chronic Lyme disease. Nat. Med. 5, 1375-1382 (1999) 
178. Dinerman, H. \& Steere, A. C. Lyme disease associated with fibromyalgia. Ann. Intern. Med. 117, 281-285 (1992).

179. Batheja, S., Nields, J. A., Landa, A. \& Fallon, B. A Post-treatment Lyme syndrome and central sensitization. J. Neuropsychiatry Clin. Neurosci. 25, 176-186 (2013)

180. Strle, K., Stupica, D., Drouin, E. E., Steere, A. C. \& Strle, F. Elevated levels of IL-23 in a subset of patients with post-Lyme disease symptoms following erythema migrans. Clin. Infect. Dis. 58, 372-380 (2014).

181. Chandra, A. et al. Anti-neural antibody reactivity in patients with a history of Lyme borreliosis and persistent symptoms. Brain Behav. Immun. 24 1018-1024 (2010)

182. Feder, H. M. et al. A critical appraisal of "chronic Lyme disease”. N. Engl. J. Med. 357, 1422-1430 (2007).

183. Patrick, D. M. et al. Lyme disease diagnosed by alternative methods: a phenotype similar to that of chronic fatigue syndrome. Clin. Infect. Dis. 61 1084-1091 (2015)

184. Bacon, R. M. et al. Serodiagnosis of Lyme disease by kinetic enzyme-linked immunosorbent assay using recombinant VIsE1 or peptide antigens of Borrelia burgdorferi compared with 2-tiered testing using whole-cell lysates. J. Infect. Dis. 187, 1187-1199 (2003).

This detailed study provides data on the efficacy of standard two-tiered testing for Lyme disease using ELISA and western blot and compares this approach with second-generation peptide-based ELISAs.

185. Goettner, G. et al. Improvement of Lyme borreliosis serodiagnosis by a newly developed recombinant immunoglobulin $\mathrm{G}(\mathrm{IgG})$ and IgM line immunoblot assay and addition of VIsE and DbpA homologues. J. Clin. Microbiol. 43, 3602-3609 (2005).

186. Seriburi, V., Ndukwe, N., Chang, Z., Cox, M. E. \& Wormser, G. P. High frequency of false positive IgM immunoblots for Borrelia burgdorferi in clinical practice. Clin. Microbiol. Infect. 18, 1236-1240 (2012).

187. Branda, J. A., Linskey, K., Kim, Y. A., Steere, A. C. \& Ferraro, M. J. Two-tiered antibody testing for Lyme disease with use of 2 enzyme immunoassays, a wholecell sonicate enzyme immunoassay followed by a VIsE C6 peptide enzyme immunoassay. Clin. Infect. Dis. $\mathbf{5 3}$ 541-547 (2011)

This study reports that a modified two-tiered assay for Lyme disease using two commercially available enzyme immunoassays was more sensitive during early disease and provided equivalent specificity as standard two-tiered testing with ELISA and western blot.

188. Wormser, G. P. et al. Single-tier testing with the C6 peptide ELISA kit compared with two-tier testing for Lyme disease. Diagn. Microbiol. Infect. Dis. 75, 9-15 (2013)

189. Wormser, G. P. et al. Comparative cost-effectiveness of two-tiered testing strategies for serodiagnosis of Lyme disease with noncutaneous manifestations. J. Clin. Microbiol. 51, 4045-4049 (2013).

190. Gomes-Solecki, M. J. et al. A first-tier rapid assay for the serodiagnosis of Borrelia burgdorferi infection. Arch. Intern. Med. 161, 2015-2020 (2001).

191. Cerar, T. et al. Diagnostic value of cytokines and chemokines in Lyme neuroborreliosis. Clin. Vaccine Immunol. 20, 1578-1584 (2013).

192. Hytönen, J. et al. CXCL13 and neopterin concentrations in cerebrospinal fluid of patients with Lyme neuroborreliosis and other diseases that cause neuroinflammation. J. Neuroinflammation 11, 103 (2014).

193. Schmidt, C. et al. A prospective study on the role of CXCL13 in Lyme neuroborreliosis. Neurology 76 , 1051-1058 (2011)

94. van Burgel, N. D., Brandenburg, A., Gerritsen, H. J., Kroes, A. C. M. \& van Dam, A. P. High sensitivity and specificity of the C6-peptide ELISA on cerebrospinal fluid in Lyme neuroborreliosis patients. Clin. Microbiol. Infect. 17, 1495-1500 (2011)

195. Molins, C. R. et al. Development of a metabolic biosignature for detection of early Lyme disease. Clin. Infect. Dis. 60, 1767-1775 (2015).

196. Steere, A. C. et al. Successful parenteral penicillin therapy of established Lyme arthritis. N. Engl. J. Med. 312, 869-874 (1985)

197. Jowett, N., Gaudin, R. A., Banks, C. A. \& Hadlock, T. A. Steroid use in Lyme disease-associated facial palsy is associated with worse long-term outcomes. Laryngoscope http://dx.doi.org/10.1002/lary.26273 (2016).

198. Kugeler, K. J., Jordan, R. A., Schulze, T. L., Griffith, K. S. \& Mead, P. S. Will culling white-tailed deer prevent Lyme disease? Zoonoses Public Health 63, 337-345 (2016)

199. Pound, J. M., Miller, J. A., George, J. E. \& Fish, D. The United States Department of Agriculture Northeast Area-wide Tick Control Project: history and protocol. Vector Borne Zoonotic Dis. 9, 365-370 (2009).

200. Richer, L. M. et al. Reservoir targeted vaccine against Borrelia burgdorferi: a new strategy to prevent Lyme disease transmission. J. Infect. Dis. 209, 1972-1980 (2014)

201. Ostfeld, R. S. Lyme Disease: The Ecology of a Complex System (Oxford Univ. Press, 2011)

202. Hinckley, A. F. et al. Effectiveness of residential acaricides to prevent Lyme and other tick-borne diseases in humans. J. Infect. Dis. 214, 182-188 (2016)

203. Töpfer, K. H. \& Straubinger, R. K. Characterization of the humoral immune response in dogs after vaccination against the Lyme borreliosis agent $A$ study with five commercial vaccines using two different vaccination schedules. Vaccine 25, 314-326 (2007)

204. Aronowitz, R. A. The rise and fall of the Lyme disease vaccines: a cautionary tale for risk interventions in American medicine and public health. Milbank 0.90 250-277 (2012) This article provides an insightful analysis of both the scientific and the sociopolitical dynamics, which led to the withdrawal of the first commercially available Lyme disease vaccine after 4 years on the market in the United States.

205. Poland, G. A. Vaccines against Lyme disease: what happened and what lessons can we learn? Clin. Infect. Dis. 52, s253-s258 (2011)

206. Shadick, N. A., Liang, M. H., Phillips, C. B., Fossel, K $\&$ Kuntz, K. M. The cost-effectiveness of vaccination against Lyme disease. Arch. Intern. Med. 161 554-561 (2001).

207. Kung, F et al. A Borrelia burgdorferi surface-exposed transmembrane protein lacking detectable immune responses supports pathogen persistence and constitutes a vaccine target. J. Infect. Dis. 213, 1786-1795 (2016)

208. Schuijt, T. J., Hovius, J. W., van der Poll, T., van Dam, A. P. \& Fikrig, E. Lyme borreliosis vaccination: the facts, the challenge, the future. Trends Parasitol. 27, 40-47 (2011).

209. Wressnigg, N. et al. Safety and immunogenicity of a novel multivalent OspA vaccine against Lyme borreliosis in healthy adults: a double-blind, randomised, dose-escalation phase $1 / 2$ trial. Lancet Infect. Dis. 13, 680-689 (2013).

210. Wikel, S. K. Host immunity to ticks. Annu. Rev. Entomol 41, 1-22 (1996).

211. Dai, J. et al. Antibodies against a tick protein, Salp 15 protect mice from the Lyme disease agent. Cell Host Microbe 6, 482-492 (2009).

Using a mouse model, this study presents a novel approach for vaccination against not only the agent of Lyme borreliosis but also other co-infecting agents, which involves immunization with a tick protein that induces antibodies to protect against tick attachment.
212. Schuijt, T. J. et al. A tick mannose-binding lectin inhibitor interferes with the vertebrate complement cascade to enhance transmission of the Lyme disease agent. Cell Host Microbe 10, 136-146 (2011).

213. Plotkin, S. A. Need for a new Lyme disease vaccine. N. Engl. J. Med. 375, 911-913 (2016).

214. Engstrom, S. M., Shoop, E. \& Johnson, R. C. Immunoblot interpretation criteria for serodiagnosis of early Lyme disease. J. Clin. Microbiol. 33, 419-427 (1995).

215. Dressler, F., Whalen, J. A., Reinhardt, B. N \& Steere, A. C. Western blotting in the serodiagnosis of Lyme disease. J. Infect. Dis. 167, 392-400 (1993).

216. Reiber, H. \& Peter, J. B. Cerebrospinal fluid analysis: disease-related data patterns and evaluation programs. J. Neurol. Sci. 184, 101-122 (2001).

217. Lindgren, E. \& Jaenson, T. G. T. Lyme borreliosis in Europe: influences of climate and climate change, epidemiology, ecology and adaptation measures. WHO Europe http://www.euro.who.int/ data/assets/ pdf file/0006/96819/E89522.pdf (2014).

218. Moore, S. M., Eisen, R. J., Monaghan, A. \& Mead, P. Meteorological influences on the seasonality of Lyme disease in the United States. Am. J. Trop. Med. Hyg. 90, 486-496 (2014)

219. Korenberg, E. I., Gorelova, N. B. \& Kovalevskii, Y. V. in Lyme Borreliosis: Biology, Epidemiology and Control (eds Gray, J., Kahl, O., Lane, R. S. \& Stanek, G.) 175-200 (CABI, 2002)

220. Masuzawa, T. Terrestrial distribution of the Lyme borreliosis agent Borrelia burgdorferi sensu lato in East Asia. Jpn J. Infect. Dis. 57, 229-235 (2004).

221. Ogden, N. H., Lindsay, L. R., Morshed, M., Sockett, P. N. \& Artsob, H. The emergence of Lyme disease in Canada. CMAJ 180, 1221-1224 (2009).

222. Steere, A. C., Coburn, J. \& Glickstein, L. The emergence of Lyme disease. J. Clin. Invest. 113 1093-1101 (2004)

\section{Acknowledgements}

A.C.S. has received funding from the US National Institutes of Health (NIH) (R01 Al-101175), the English-BonterMitchell Foundation and the Eshe Fund. FS was supported by the Slovenian Research Agency (P3-0296). L.T.H. has received funding from the NIH (R21 Al-126757, R21 Al-103905, U01 Al-109656 and R21 Al-111317) and the Steven and Alexandra Cohen Foundation. J A.B. has received funding from the NIH (R21 Al-119457). X.L. has received funding from the NIH (R01 Al-103173). J.W.R.H. is sup ported by the European Commission (grant agreement 602272). However, none of these funding sources had a role in the preparation or approval of this manuscript.

\section{Author contributions}

Introduction (A.C.S.); Epidemiology (P.S.M.); Mechanisms/ pathophysiology (L.T.H. and X.L.); Diagnosis, screening and prevention (A.C.S and F.S.); Management (G.P.W. and F.S.); Quality of life (A.C.S. and F.S.); Outlook (J.A.B., A.C.S., P.S.M. and J.W.R.H.); Overview of Primer (A.C.S.).

\section{Competing interests}

A.C.S declares grant support from Immunetics, Inc. and Viramed. F.S has served as a consultant to Baxter Biosciences regarding Lyme vaccine development and has been a member of the steering committee of the European Society of Clinical Microbiology and Infectious Diseases Study Group on Lyme Borreliosis (ESGBOR). G.P.W. has received research grants from Immunetics Inc., Institute for Systems Biology, Rarecyte, Inc. and Quidel Corporation. G.P.W. also owns equity in Abbott, has been an expert witness in malpractice cases involving Lyme borreliosis and is an unpaid board member of the American Lyme Disease Foundation. J.A.B. declares grant support from Immunetics, Inc. and Diasorin. J.W.R.H. is a member of the steering committee of ESGBOR. L.T.H., X.L. and P.S.M. declare no competing interests. 
CORRECTION

\section{Lyme borreliosis}

Allen C. Steere, Franc Strle, Gary P. Wormser, Linden T. Hu, John A. Branda, Joppe W. R. Hovius, Xin Li and Paul S. Mead

Nature Reviews Disease Primers 2, 16090 (2016)

In the version of the article originally published, it was incorrectly stated that Figure $3 \mathrm{~b}$ is a 3D model generated by cryo-electron tomography. This has now been corrected. 